\title{
Catalytic Oxidations with Meta-Chloroperoxybenzoic Acid ( $m$-CPBA) and Mono- and Polynuclear Complexes of Nickel: A Mechanistic Outlook
}

\author{
Dmytro S. Nesterov (D) and Oksana V. Nesterova *(D) \\ Centro de Química Estrutural, Instituto Superior Técnico, Universidade de Lisboa, Av. Rovisco Pais, \\ 1049-001 Lisboa, Portugal; dmytro.nesterov@tecnico.ulisboa.pt \\ * Correspondence: oksana.nesterova@tecnico.ulisboa.pt
}

Citation: Nesterov, D.S.; Nesterova, O.V. Catalytic Oxidations with Meta-Chloroperoxybenzoic Acid ( $m$-CPBA) and Mono- and Polynuclear Complexes of Nickel: A Mechanistic Outlook. Catalysts 2021, 11, 1148. https://doi.org/10.3390/ catal11101148

Academic Editor: Samuel Dagorne

Received: 18 August 2021

Accepted: 23 September 2021

Published: 25 September 2021

Publisher's Note: MDPI stays neutral with regard to jurisdictional claims in published maps and institutional affiliations.

Copyright: (c) 2021 by the authors. Licensee MDPI, Basel, Switzerland. This article is an open access article distributed under the terms and conditions of the Creative Commons Attribution (CC BY) license (https:/ / creativecommons.org/licenses/by/ $4.0 /)$.

\begin{abstract}
Selective catalytic functionalization of organic substrates using peroxides as terminal oxidants remains a challenge in modern chemistry. The high complexity of interactions between metal catalysts and organic peroxide compounds complicates the targeted construction of efficient catalytic systems. Among the members of the peroxide family, $m$-chloroperoxybenzoic acid ( $m$-CPBA) exhibits quite complex behavior, where numerous reactive species could be formed upon reaction with a metal complex catalyst. Although $m$-CPBA finds plenty of applications in fine organic synthesis and catalysis, the factors that discriminate its decomposition routes under catalytic conditions are still poorly understood. The present review covers the advances in catalytic $\mathrm{C}-\mathrm{H}$ oxidation and olefine epoxidation with $m$-CPBA catalyzed by mono- and polynuclear complexes of nickel, a cheap and abundant first-row transition metal. The reaction mechanisms are critically discussed, with special attention to the $\mathrm{O}-\mathrm{O}$ bond splitting route. Selectivity parameters using recognized model hydrocarbon substrates are summarized and important factors that could improve further catalytic studies are outlined.
\end{abstract}

Keywords: $m$ CPBA; nickel complexes; oxidative catalysis; free radicals; cyclohexane oxidation; stereoselectivity

\section{Introduction}

Peroxides constitute a class of compounds of exhaustive importance in the current chemical industry as well as in laboratory practice and biological studies [1-4]. Being strong oxidants, peroxide compounds often show low selectivity and do not discriminate chemical groups of close reactivities, which represents a drawback for targeted synthesis. Catalytic activation is the best way to control the peroxide's power $[5,6]$. The natural enzymatic systems demonstrate an exciting example of such control, where the metalcontaining active centers can hydroxylate organic substrates using peroxides as terminal oxidants $[7,8]$. While the simplest and most used peroxide compound, hydrogen peroxide, is a cheap and readily available oxidant [9], the organic peroxides ( $\mathrm{ROOH}$ or ROOR') reveal advantages in terms of higher stability and selectivity-important features for fine organic synthesis. Moreover, organic peroxides can produce highly active and selective intermediates in combination with auxiliary reagents [10-12]. However, in contrast to $\mathrm{H}_{2} \mathrm{O}_{2}$, organic peroxides may generate a broader range of radical species [13]. Therefore, the role of the catalyst is not only the activate the $\mathrm{O}-\mathrm{O}$ bond in a desired way, but also to efficiently suppress the minor reaction pathways leading to the formation of side attacking species (such as free radicals). Among all organic peroxides of practical significance, $m$ chloroperoxybenzoic acid (m-CPBA) shows some of the most complex behavior [13-15]. The oxidizing potential of $m-C P B A$ is sufficient even for the hydroxylation of methane using P450 enzyme [16] or its model systems (iron porphyrin complexes) as catalysts [17]. Moreover, $m$-CPBA is commonly used for asymmetric catalytic epoxidations and other 
processes dealing with the activation and functionalization of $\mathrm{C}-\mathrm{H}$ bonds-one of the most challenging reactions in modern chemistry [18-20]. Typically, the role of a catalyst in a highly selective peroxide system is to form high-valence metal-oxo (HVMO) species, whose reactivity can be further controlled by the ligand's nature [18,21]. Although $m$-CPBA is a convenient and easy-to-handle terminal oxidant for such reactions, it is prone to the formation of a series of $\mathrm{O}$ - and $\mathrm{C}$-centered radical species, all of which are capable of $\mathrm{H}$ abstraction (Scheme 1). Moreover, all these species show different degrees of reactivity and selectivity, in this way interfering with the main (non-free radical) reaction mechanism and complicating the establishment of the $\mathrm{C}-\mathrm{H}$ attacking species. To date, the factors that favor the $\mathrm{O}-\mathrm{O}$ bond homolysis of $m$-CPBA and trigger its free radical activity are still to be established.

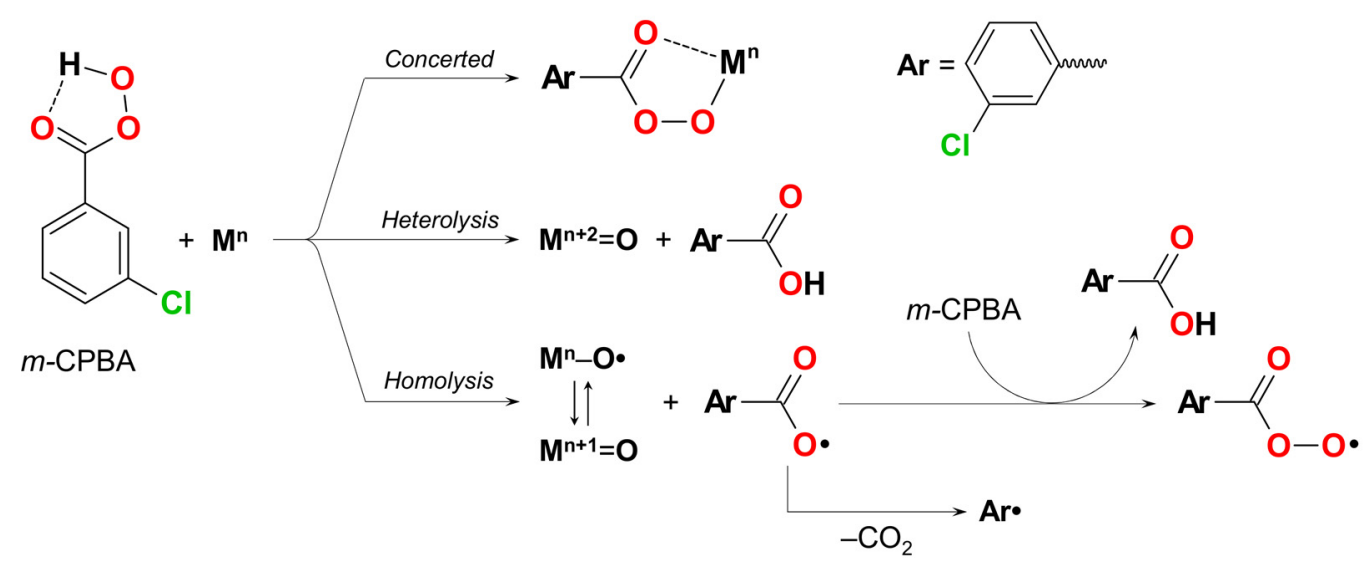

Scheme 1. General representation of the intermediates formed upon reaction of $m$-CPBA with a metal center depending on the reaction mechanism. All depicted species, except for $m$-chlorobenzoic acid, $\operatorname{ArC}(\mathrm{O}) \mathrm{OH}$, are capable of $\mathrm{H}$ abstraction. Charges are not shown.

Mono- and polynuclear compounds of nickel have attracted great attention as catalysts for $\mathrm{C}-\mathrm{H}$ oxidation and epoxidation with peroxides, particularly $m$-CPBA [22]. However, the nature of $\mathrm{C}-\mathrm{H}$ attacking species has become a matter of heated debate [23]. Complexes of nickel demonstrate high catalytic efficiency and, furthermore, Ni(III) HVMO intermediates are stable enough to be trapped with convenient methods such as ESI-MS and EPR spectroscopies [24-26]. On the other hand, there are signs of a significant contribution of free radical reactions, where HVMO nickel species could be formed simply as a by-product. Thus, while the initial reports suggested the metal-mediated reaction mechanism [27], the latest studies indicate free organic radicals as the main $\mathrm{C}-\mathrm{H}$ attacking species in $\mathrm{Ni} / m$-CPBA catalytic systems [23].

The set of bond-, regio- and stereoselectivity parameters of a catalytic system is an important indicator for the nature of $\mathrm{C}-\mathrm{H}$ attacking species $[6,28]$. The typical model substrates used for bond selectivity studies are methylcyclohexane and adamantane. However, the difference between $3^{\circ}$ and $2^{\circ}$ reactivities itself (Scheme 2 ) does not carefully distinguish between the attacking species, which may fall within the same region of $3^{\circ}: 2^{\circ}$ ratios. One of the most efficient tests for the presence of free radicals is the oxidation of tertiary $\mathrm{C}-\mathrm{H}$ bonds, which allows epimerization of the stereoconfiguration [29-32]. The typical substrates are dimethylcyclohexanes or decahydronapthalenes (Scheme 3) [30,33,34]. In the event that the reaction proceeds completely through the long-lived alkyl radicals (as expected for $\mathrm{H}$ abstraction by $\mathrm{RO} \bullet$ or RC• species, Scheme 1), the cis- and trans-products will form in nearly equal quantities, independently of the starting stereoconfiguration of the substrate. Unfortunately, this simple test is often omitted in catalytic studies of $m$-CPBA, although it could give a direct answer regarding the existence of long-lived free radicals. In this review, we focus on the nickel mono- and polynuclear complexes as catalysts for $\mathrm{C}-\mathrm{H}$ oxidation with $m$-CPBA, with special attention paid to selectivity studies and the nature of attacking species. 


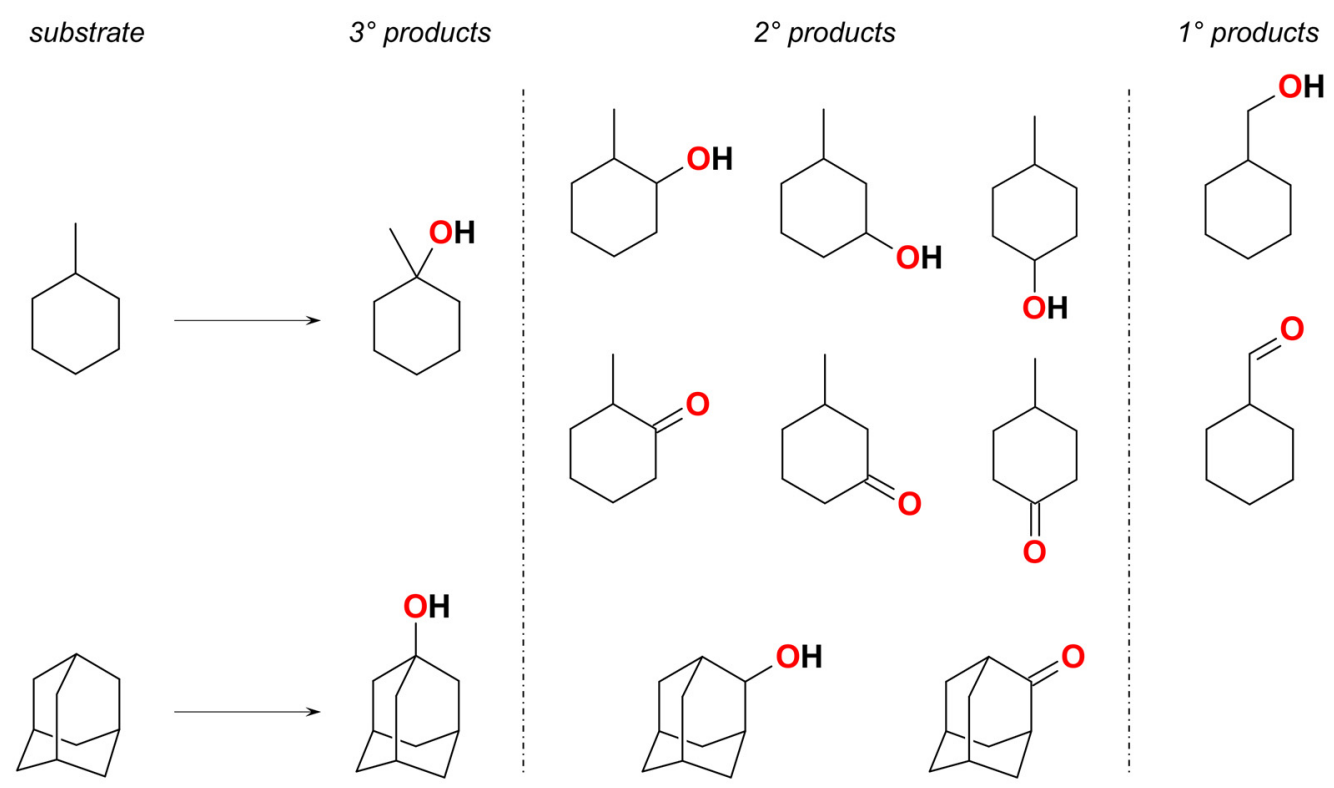

Scheme 2. Typical model substrates and their products used for determination of $3^{\circ}: 2^{\circ}: 1^{\circ}$ and $3^{\circ}: 2^{\circ}$ bond selectivity of the catalytic C-H oxidation.

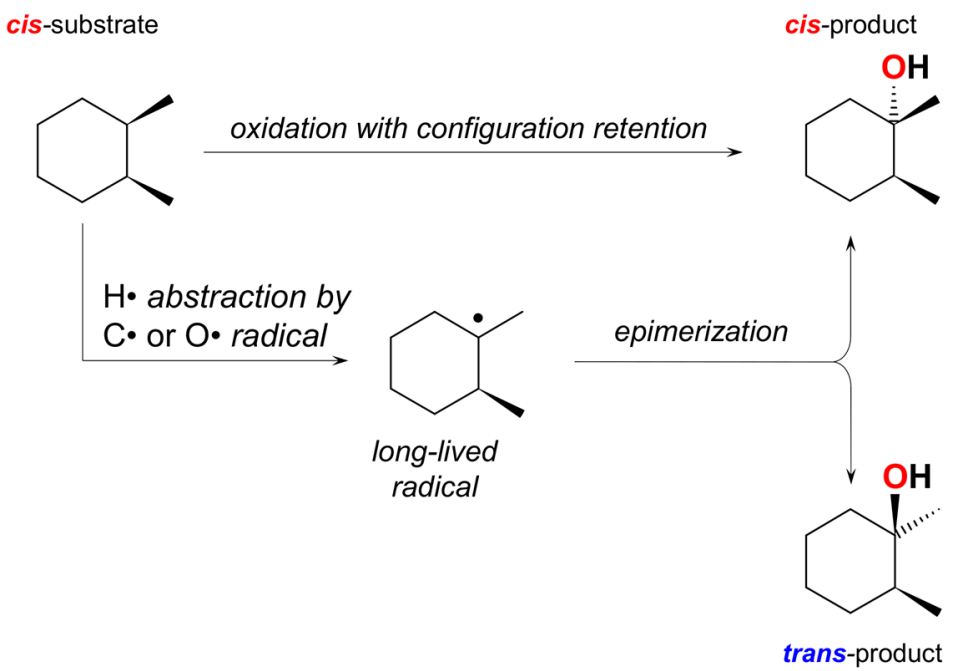

Scheme 3. Hydroxylation of a tertiary $\mathrm{C}-\mathrm{H}$ bond of cis-1,2-dimethylcyclohexane as a test system for the presence of long-lived alkyl radical intermediates (the latter results in a nearly 1:1 ratio of cis- and trans-products).

\section{Discussion}

The catalytic interaction of nickel complexes with $m$-CPBA was practically not studied before the report in 2006 of the pronounced catalytic activity of the $\left[\mathrm{Ni}^{\mathrm{II}}\left(\mathrm{L}^{1}\right)(\mathrm{OAc})\left(\mathrm{H}_{2} \mathrm{O}\right)\right] \mathrm{BPh}_{4}$ (Ni1) $\left(\mathrm{L}^{1}=\right.$ tris(2-pyridylmethyl)amine) compound in the oxidation of hydrocarbons (Figure 1) [35]. The polypyridyl ligand TPA and its derivatives are known to stabilize oxo and peroxo complexes of iron [36]. Although the respective nickel species are expected to be less stable, they could also be stabilized by the $\mathrm{L}^{1}$ family. The complex Ni1 catalyzes the oxidation of cyclohexane (Scheme 4), cyclooctane, adamantane and ethylbenzene to the respective alcohols and ketones, with a maximum TON of 676 (for cyclooctane), which corresponds to a $68 \%$ yield based on the oxidant. Cyclohexane oxidation revealed similar reactivity, with TON of 656, while ethylbenzene was the least reactive substrate, as evidenced by the respective TON of 256. Only trace amounts of $\varepsilon$-caprolactone by-product were detected in the oxidation of cyclohexane. Adamantane was oxidized with $3^{\circ}: 2^{\circ}$ bond selectivity of 13:1. All reactions proceeded in the mixed $\mathrm{CH}_{3} \mathrm{CN} / \mathrm{CH}_{2} \mathrm{Cl}_{2}$ (3:1) media. 
Complexes of cobalt, iron and manganese with the same $\mathrm{L}^{1}$ ligand were tested and showed lower catalytic activity under similar conditions. The authors proposed the participation of $\mathrm{NiO}^{+}$species as reaction intermediates [35].<smiles>c1ccc(CN(Cc2ccccn2)Cc2ccccn2)nc1</smiles>

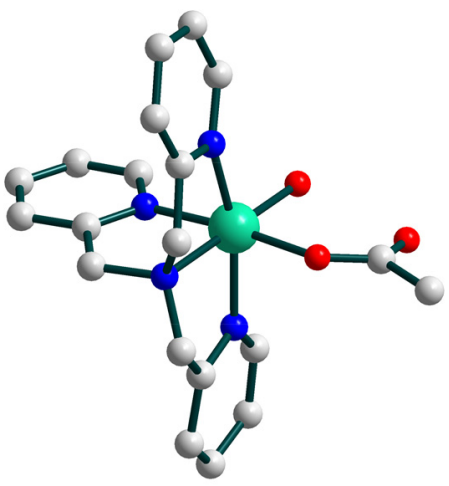

Figure 1. (Left) Schematic representation of the ligand $\mathrm{L}^{1}$. (Right) Molecular structure (CSD refcode XESVEX) of the complex $\left[\mathrm{Ni}^{\mathrm{II}}\left(\mathrm{L}^{1}\right)(\mathrm{OAc})\left(\mathrm{H}_{2} \mathrm{O}\right)\right] \mathrm{BPh}_{4}$ (Ni1) [35]. The hydrogen atoms and the uncoordinated $\mathrm{BPh}_{4}$ anion are omitted for clarity. Color scheme: $\mathrm{Ni}$, light green; $\mathrm{O}$, red; $\mathrm{N}$, blue; C, grey.

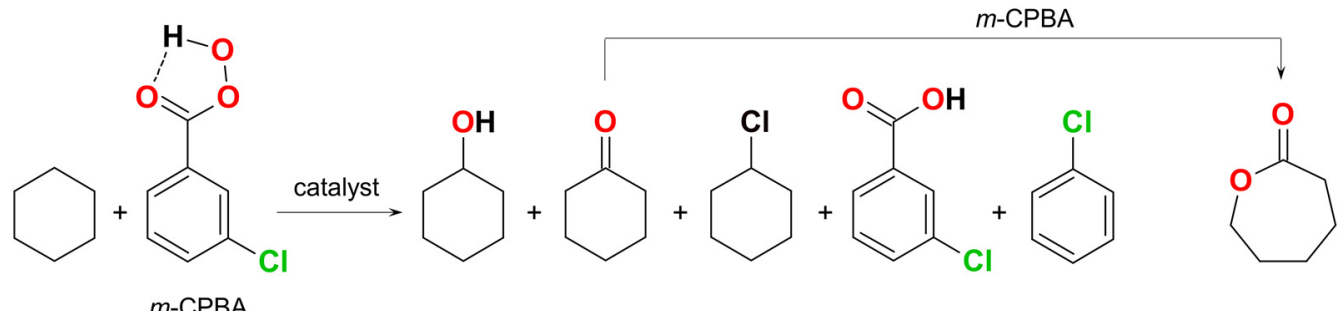

Scheme 4. Oxidation of cyclohexane, a typical model reaction used for evaluation of the catalytic activities of the discussed complexes.

A series of coordination compounds of nickel with tris(2-pyridylmethyl)amino, bis(2pyridylmethyl)amino and bis(2-pyridylethyl)amino ligands $\mathrm{L}^{1}-\mathrm{L}^{3}$ (Figures 1 and 2, left) have been investigated with the aim of understanding the influence of the ligand on the catalytic activity [27]. The highest TON in the oxidation of cyclohexane (745 for sum of cyclohexanol and cyclohexanone) was exhibited by the complex $\left[\mathrm{Ni}^{\mathrm{II}}\left(\mathrm{L}^{2 \mathrm{a}}\right)(\mathrm{OAc})(\mathrm{MeOH})\right] \mathrm{BPh}_{4}$ (Ni2) ( ${ }^{2 a}=6$-[N,N-bis(2-pyridylmethyl)aminomethyl]-2,4-di-tert-butylphenol) (Figure 2, right), showing the alcohol/ketone ratio of 7.5. An important observation was the elevated yield of chlorobenzene, whose amounts reached $50 \%$ based on the other products. Since chlorobenzene originates from the rapid decarboxylation of the $m$-chlorobenzoate radical, homolytic splitting of the $m$-CPBA O-O bond was assumed as a principal route of formation of the radical nickel-oxo species $\mathrm{Ni}^{\mathrm{II}}-\mathrm{O} \bullet$ (Scheme 5). The overall reaction mechanism proposed by the authors [27] foresees the involvement of two $m$-CPBA molecules per catalytic cycle and one product molecule. This limits the theoretical yield of products to $50 \%$ based on the oxidant. However, the experimentally documented yields reach $60-70 \%$, in this way contradicting the proposed overall mechanism [27]. 
<smiles>[R]N(Cc1ccccn1)Cc1ccccn1</smiles>

$L^{2}$<smiles>[R]N(CCc1ccccn1)CCc1ccccn1</smiles>

$\mathrm{L}^{3}$<smiles>Cc1ccccc1</smiles><smiles>Cc1cc(C(C)(C)C)cc(C(C)(C)C)c1O</smiles>

L3a<smiles>Cc1ccccc1</smiles>

$L^{3 b}$<smiles>CCc1ccccn1</smiles>

$\mathrm{L}^{3 \mathrm{c}}$

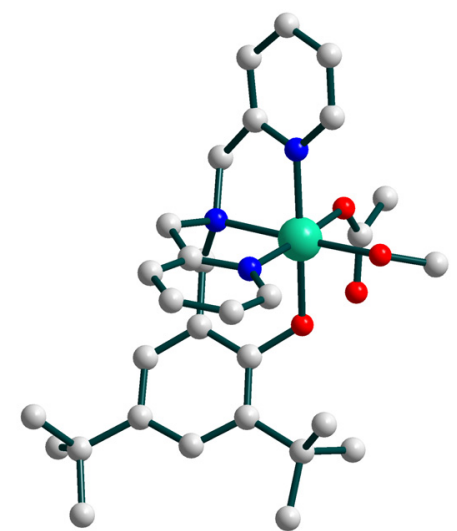

Figure 2. (Left) Schematic representation of the ligand families $\mathrm{L}^{2}$ and $\mathrm{L}^{3}$. (Right) Molecular structure (CSD refcode LEYSUE) of the complex $\left[\mathrm{Ni}^{\mathrm{II}}\left(\mathrm{L}^{2 \mathrm{a}}\right)(\mathrm{OAc})(\mathrm{MeOH})\right] \mathrm{BPh}_{4}(\mathrm{Ni2})$ [27]. The hydrogen atoms are omitted for clarity. Color scheme: $\mathrm{Ni}$, light green; $\mathrm{O}$, red; $\mathrm{N}$, blue; $\mathrm{C}$, grey.

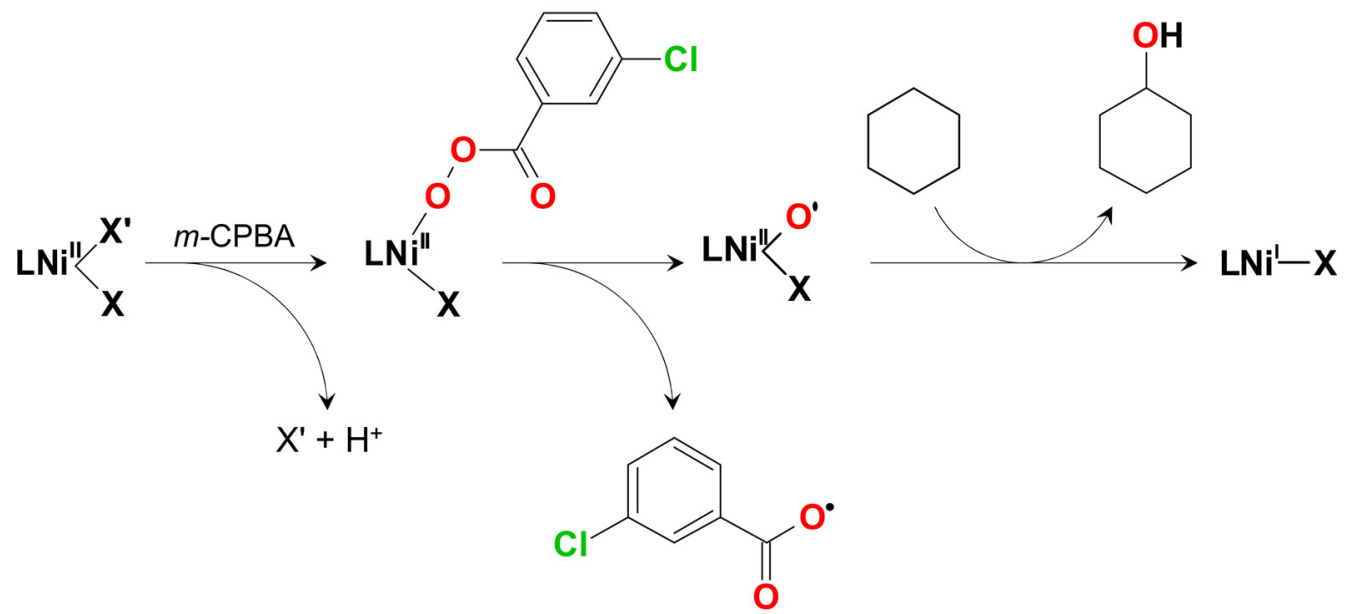

Scheme 5. Fragment of the proposed catalytic mechanism showing formation of $\mathrm{Ni}^{\mathrm{II}}-\mathrm{O} \bullet$ species and its reactivity towards hydroxylation of cyclohexane [27]. The charges are not shown.

Similar results in cyclohexane oxidation (Scheme 4) were obtained for a series of $\mathrm{Ni}$ (II) complexes with tetradentate tripodal $\mathrm{N}$-donor ligands $\mathrm{L}^{4}$ (Figure 3, left) [37]. The highest yields of products $(73 \%)$ were observed for the catalyst $\left[\mathrm{Ni}^{\mathrm{II}}\left(\mathrm{L}^{4 \mathrm{a}}\right)\left(\mathrm{H}_{2} \mathrm{O}\right)\left(\mathrm{CH}_{3} \mathrm{CN}\right)\right](\mathrm{ClO})_{2}$ (Ni3) ( ${ }^{4 a}=N, N$-dimethyl- $N^{\prime}, N^{\prime}$-bis(pyrid-2-ylmethyl)ethane-1,2-diamine). Oxidation of cumene catalyzed by $\mathrm{Ni3}$ afforded 2-phenyl-2-propanol in a $44 \%$ yield $(\mathrm{TON}=438$ ). For ethylbenzene, a TON of 443 was observed, which corresponds to a yield of $44 \%$. In contrast to cumene, oxidation of ethylbenzene afforded a mixture of alcohol and ketone, with the respective ratio of 3.6. The $3^{\circ}: 2^{\circ}$ bond selectivity in adamantane oxidation ranged from 12.5 to 17.3. The amounts of chlorobenzene by-products in the reactions with $\mathrm{Ni3}$ were nearly the same as those for the Ni2 catalyst. Hence, the $\mathrm{C}-\mathrm{H}$ bond attacking species was proposed to be $\mathrm{Ni}^{\mathrm{II}}-\mathrm{O} \bullet$ (Scheme 5). 


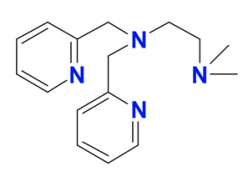

$\mathrm{L}^{4 a}$

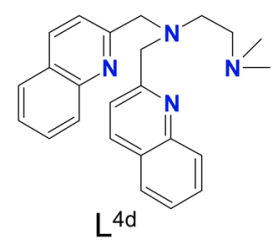

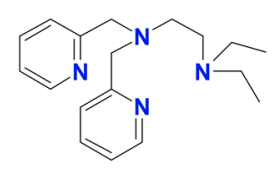

$\mathrm{L} 4 \mathrm{~b}$

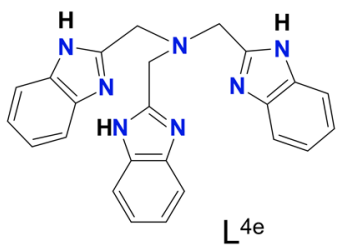

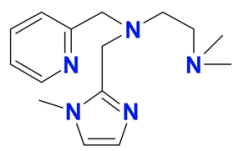

$\mathrm{L}^{4 \mathrm{c}}$

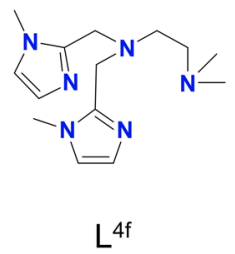

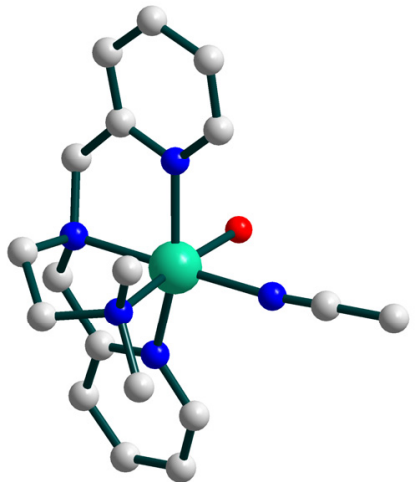

Figure 3. (Left) Schematic representation of the ligand family L ${ }^{4}$. (Right) Molecular structure (CSD refcode EXUCAC) of the complex $\left[\mathrm{Ni}^{\mathrm{II}}\left(\mathrm{L}^{4 \mathrm{a}}\right)\left(\mathrm{H}_{2} \mathrm{O}\right)\left(\mathrm{CH}_{3} \mathrm{CN}\right)\right](\mathrm{ClO})_{2}(\mathrm{Ni3})$ [37]. The hydrogen atoms are omitted for clarity. Color scheme: $\mathrm{Ni}$, light green; $\mathrm{O}$, red; $\mathrm{N}$, blue; $\mathrm{C}$, grey.

A family of nickel compounds with pentadentate $\mathrm{N}$-donor ligands of polypyridyl type (Figure 4, left) were investigated as catalysts for the mild oxidation of alkanes with $m$-CPBA [38]. All complexes of this series revealed similar properties and catalytic activities. The crystal structure of the representative example $\left[\mathrm{Ni}^{\mathrm{II}}\left(\mathrm{L}^{5 \mathrm{C}}\right)\left(\mathrm{CH}_{3} \mathrm{CN}\right)\right]\left(\mathrm{BPh}_{4}\right)_{2}(\mathrm{Ni4})$ $\left(\mathrm{L}^{5 \mathrm{c}}=N\right.$-methyl- $N, N^{\prime}$-bis(pyrid-2-ylmethyl)- $N^{\prime}$-(6-methylpyrid-2-ylmethyl)ethylenediamine) is shown in Figure 4, right. The complex Ni4 catalyzes the oxidation of cyclohexane to cyclohexanol, cyclohexanone and $\varepsilon$-caprolactone (53:1:7 ratio of products; Scheme 4), with an overall TON of 484 and yield of $48 \%$ (based on the oxidant). Substantial amounts of chlorobenzene were obtained ( $75-85 \%$ based on the oxidant). Oxidation of cumene resulted in 2-phenyl-2-propanol, with a TON of 418 ( $42 \%$ of yield). Similar results have been obtained for adamantane (TON $=527$ and yield $=53 \%$ ), showing $3^{\circ}: 2^{\circ}$ bond selectivity of 11:1 for all catalysts of this type. Extensive DFT calculations revealed the high-spin $\mathrm{Ni}^{\mathrm{iI}}-\mathrm{O} \bullet$ species as the most likely high-valence intermediate, abstracting the $\mathrm{H}$ atom through the radical rebound mechanism, in a way similar to that depicted in Scheme 5. However, no further experimental efforts (e.g., UV or EPR spectroscopic measurements) to confirm the participation of the $\mathrm{Ni}^{\mathrm{II}}-\mathrm{O} \bullet$ species were made. Moreover, rather low bond selectivity in adamantane oxidation suggests the possible involvement of other $\mathrm{C}-\mathrm{H}$ attacking species.
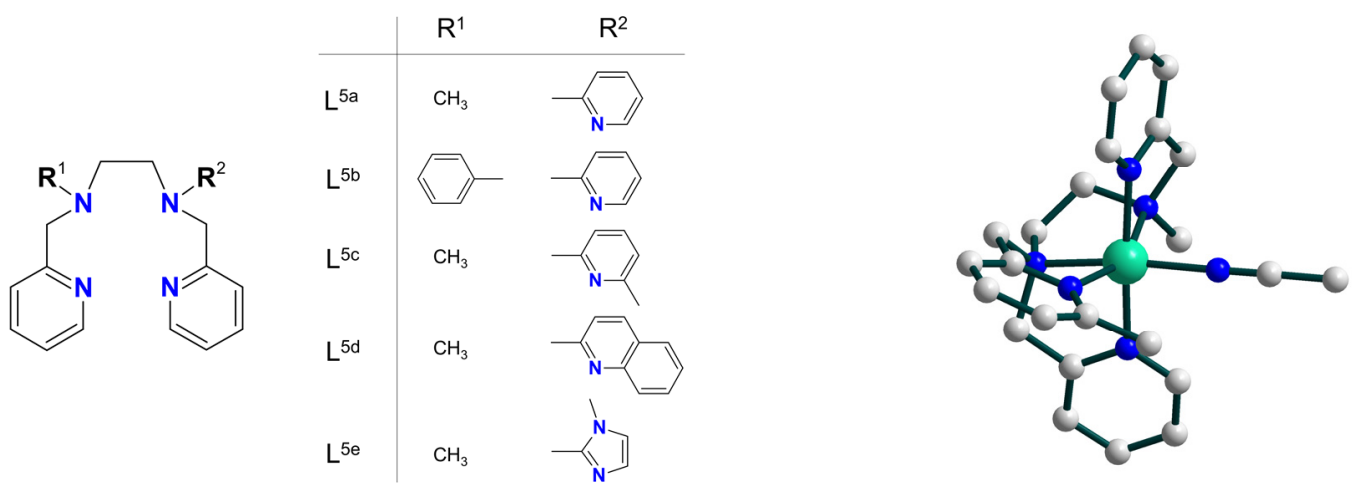

Figure 4. (Left) Schematic representation of the ligand family $\mathrm{L}^{5}$. (Right) Molecular structure (CSD refcode MOGKIE) of the complex $\left[\mathrm{Ni}^{\mathrm{II}}\left(\mathrm{L}^{5 \mathrm{c}}\right)\left(\mathrm{CH}_{3} \mathrm{CN}\right)\right]\left(\mathrm{BPh}_{4}\right)_{2}(\mathrm{Ni4})$ [38]. The hydrogen atoms and $\mathrm{BPh}_{4}$ anions are omitted for clarity. Color scheme: Ni, light green; N, blue; $\mathrm{C}$, grey.

Coordination compound $\left[\mathrm{Ni}^{\mathrm{II}}\left(\mathrm{L}^{6}\right)(\mathrm{OTf})\right](\mathrm{OTf})(\mathrm{Ni5})(\mathrm{HOTf}=$ trifluoromethanesulfonic acid $)$ bearing a tetrapodal non-aromatic $\mathrm{N}_{4}$-donor ligand $\mathrm{L}^{6}$ (tris[2-( $N$-tetramethylguanidyl)ethyl] amine) (Figure 5) was shown to favor the homolytic O-O cleavage of $m$-CPBA with the formation of a mixture of nickel(III) intermediates $\left[\mathrm{Ni}^{\mathrm{III}}(\mathrm{O})\left(\mathrm{L}^{6}\right)\right]^{+}(\mathbf{N i 5}-\mathbf{1})$ and $\left[\mathrm{Ni}^{\mathrm{III}}(\mathrm{OH})\left(\mathrm{L}^{6}\right)\right]^{2+}$ (Ni5-2) [39]. The reaction of Ni5 with one equivalent of $m$-CPBA at $-30{ }^{\circ} \mathrm{C}$ in $\mathrm{CH}_{2} \mathrm{Cl}_{2}$ afforded a deep blue solution of Ni5-1/Ni5-2 with UV absorption maxima at 464, 520 and 
$794 \mathrm{~nm}$. EPR spectra (measured at $10 \mathrm{~K}$ ) of this solution revealed two signals of rhombic $S=1 / 2$ species, attributed to geometrically different nickel(III) complexes Ni5-1 and Ni5-2. The authors excluded the possibility of the heterolytic splitting of $m$-CPBA based on the GC-MS analysis of reaction mixtures, where chlorobenzene, but not $m$-chlorobenzoic acid (a product of $\mathrm{O}-\mathrm{O}$ bond heterolysis), was detected. The signs of heterolytic splitting were observed only under the conditions of ESI-MS experiments, where peaks attributable to $\mathrm{Ni}^{\mathrm{IV}}=\mathrm{O}$ species were detected (Scheme 6 ). The mixture of metastable complexes Ni5-1/Ni52 hydroxylates (at $-30^{\circ} \mathrm{C}$ ) methylenic $\mathrm{C}-\mathrm{H}$ bonds in xanthene, 9,10-dihydroanthracene (DHA) and 1,4-cyclohexadiene at high reaction rates were comparable for oxygen transfer to $\mathrm{PPh}_{3}$. Oxidation of 1-benzyl-1,4-dihydronicotinamide with Ni5-1/Ni5-2 proceeds at least two orders faster. A large kinetic isotope effect of 3.9 was found for parallel oxidations of normal and $d_{4}$-DHA [39]. It is noteworthy that the strength of the doublet EPR signals decays along with the reduction process (Figure 6), as expected for $\mathrm{Ni}(\mathrm{III}) \rightarrow \mathrm{Ni}$ (II) transformation (the divalent nickel complex Ni5 is highly likely to be EPR-silent in the $\mathrm{X}$-band due to the large zero-field splitting [40,41]).<smiles>CN(C)C(=NCCN(CCN=C(N(C)C)N(C)C)CCN=C(N(C)C)N(C)C)N(C)C</smiles>

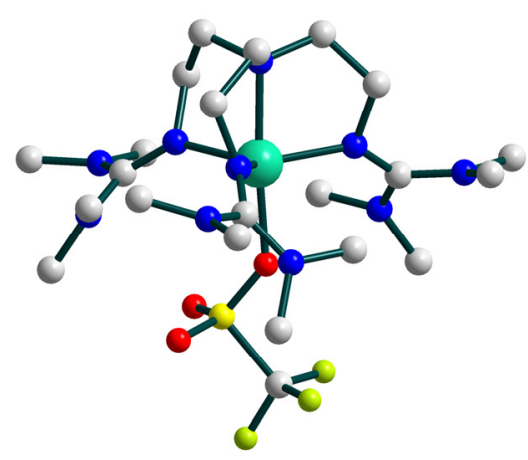

Figure 5. (Left) Schematic representation of the ligand $\mathrm{L}^{6}$. (Right) Molecular structure (CSD refcode ZARNAJ) of the complex $\left[\mathrm{Ni}^{\mathrm{II}}\left(\mathrm{L}^{6}\right)(\mathrm{OTf})\right](\mathrm{OTf})(\mathrm{Ni5})$ [39]. The hydrogen atoms and OTf anions are omitted for clarity. Color scheme: $\mathrm{Ni}$, light green; $\mathrm{O}$, red; N, blue; $\mathrm{S}$, yellow; F, yellow-green; $\mathrm{C}$, grey.

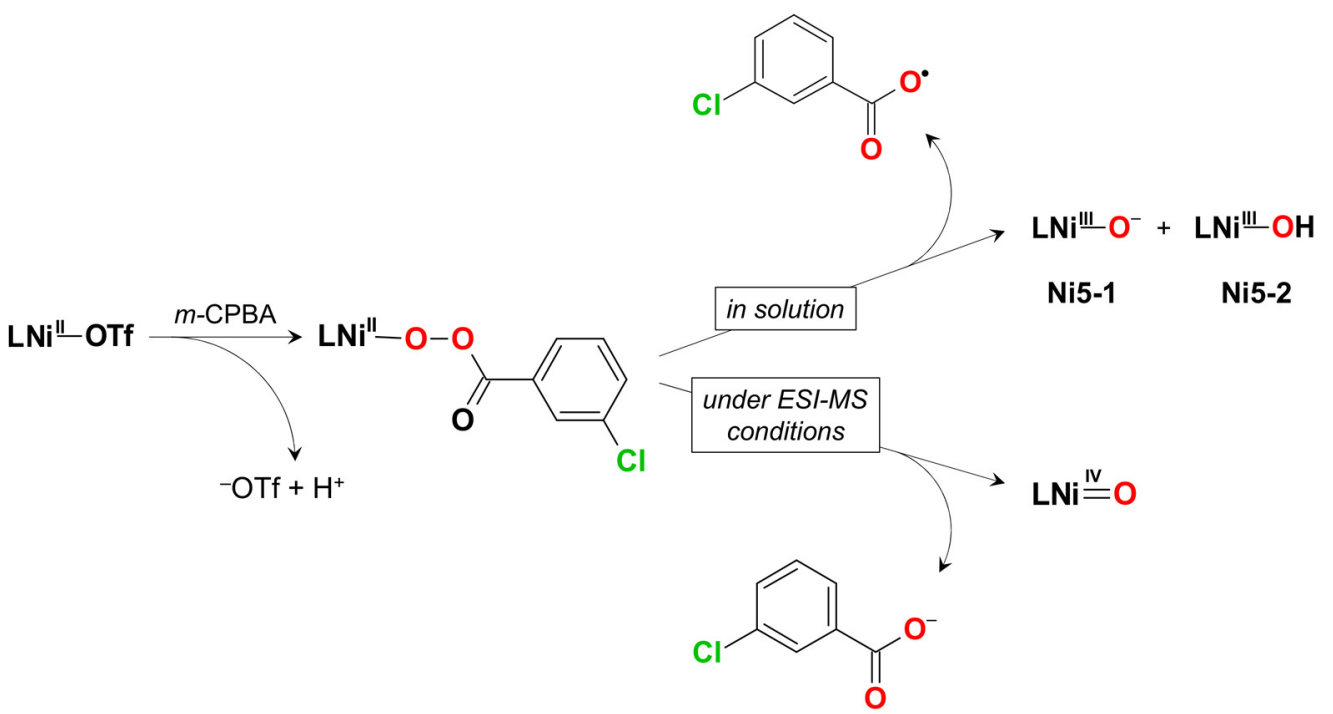

Scheme 6. Fragment of the proposed catalytic mechanism showing formation of Ni5-1 and Ni5-2 species [39]. The charges are not shown. 


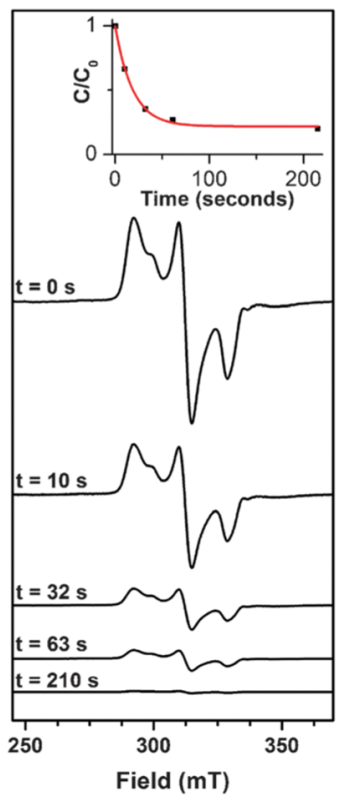

Figure 6. Decay of the doublet EPR signal assigned to the mixture of Ni5-1 and Ni5-2 species upon their reaction with $\mathrm{PPh}_{3}$. Adapted with permission from [39], Royal Society of Chemistry, 2012.

Further development in the field was achieved by employing scorpionate ligands (Figure 7, left) [42], which are known to stabilize nickel(II)-alkylperoxo species [43]. The model catalytic system comprised cyclohexane (Scheme 4) or methylcyclohexane (Scheme 2), $m$-CPBA and a nickel catalyst in $\mathrm{C}_{6} \mathrm{H}_{5} \mathrm{CF}_{3}$ or $\mathrm{CH}_{2} \mathrm{Cl}_{2}$. The maximum TONs did not exceed 42 , for $\left[\mathrm{Ni}_{2}\left(\mathrm{~L}^{7 \mathrm{a}}\right)_{2}(\mathrm{OH})_{2}\right]$ (Ni6) (Figure 7, right) [42]. The system displayed only a weak preference towards oxidation of the tertiary $\mathrm{C}-\mathrm{H}$ bond of methylcyclohexane, as evidenced by the low $3^{\circ}: 2^{\circ}$ bond selectivity of $5: 1$ (the catalyst-free test revealed $33: 1$ bond selectivity under the same conditions). Based on spectroscopic studies, the authors concluded that the mononuclear nickel(II)-acylperoxo species, formed after the reaction of Ni6 with $m$-CPBA, are able to abstract $\mathrm{H}$ atoms from $\mathrm{C}-\mathrm{H}$ bonds in a concerted mechanism (Scheme 7), although the possibility of $\mathrm{O}-\mathrm{O}$ homolysis with the formation of $\mathrm{Ni}^{\mathrm{II}}-\mathrm{O} \bullet$ and $\mathrm{Ni}^{\mathrm{III}}=\mathrm{O}$ species was not excluded. No ${ }^{18} \mathrm{O}-$ labeled oxygen in cyclohexanol was detected when oxidizing cyclohexane in the presence of $\mathrm{H}_{2}{ }^{18} \mathrm{O}$. The observation of labeled cyclohexanone, however, was mistakenly interpreted [42] as an indication of the presence of different formation pathways of cyclohexanol and cyclohexanone. Ketones are known to exchange oxygen with water [44-47]; this mechanism is the main source of ${ }^{18} \mathrm{O}$-enriched cyclohexanones in the presence of $\mathrm{H}_{2}{ }^{18} \mathrm{O}$.

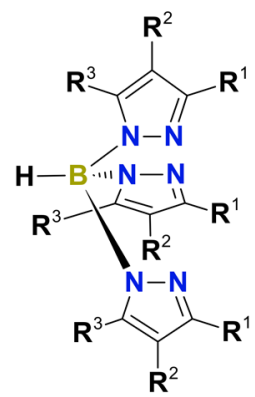

\begin{tabular}{c|ccc} 
& $\mathrm{R}^{1}$ & $\mathrm{R}^{2}$ & $\mathrm{R}^{3}$ \\
\hline $\mathrm{L}^{7 \mathrm{a}}$ & $\mathrm{CH}_{3}$ & $\mathrm{H}$ & $\mathrm{CH}_{3}$ \\
$\mathrm{~L}^{7 \mathrm{~b}}$ & $\mathrm{CH}_{3}$ & $\mathrm{Br}$ & $\mathrm{CH}_{3}$ \\
$\mathrm{~L}^{7 \mathrm{c}}$ & $\mathrm{iPr}$ & $\mathrm{H}$ & $\mathrm{iPr}$ \\
& & & \\
$\mathrm{L}^{7 \mathrm{~d}}$ & $\mathrm{iPr}$ & $\mathrm{Br}$ & $\mathrm{iPr}$
\end{tabular}

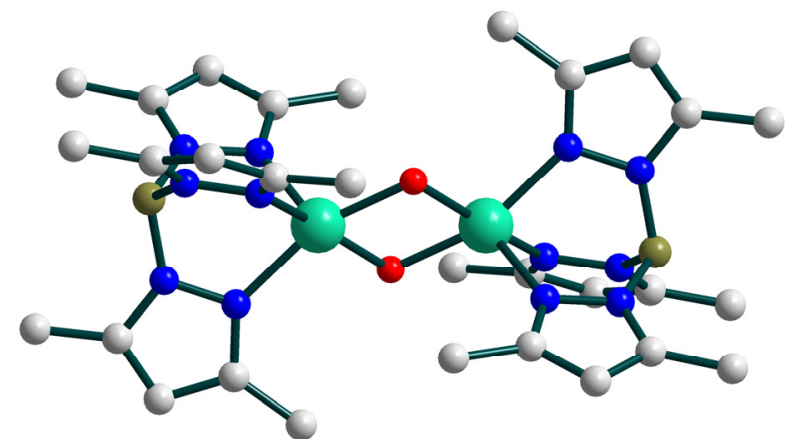

Figure 7. (Left) Schematic representation of the ligand family $\mathrm{L}^{7}$. (Right) Molecular structure (CSD refcode UFABOS) of the complex $\left[\mathrm{Ni}_{2}\left(\mathrm{~L}^{7 \mathrm{a}}\right)_{2}(\mathrm{OH})_{2}\right]$ (Ni6) [42]. The hydrogen atoms are omitted for clarity. Color scheme: Ni, light green; O, red; $\mathrm{N}$, blue; B; brown-green; $\mathrm{C}$, grey. 


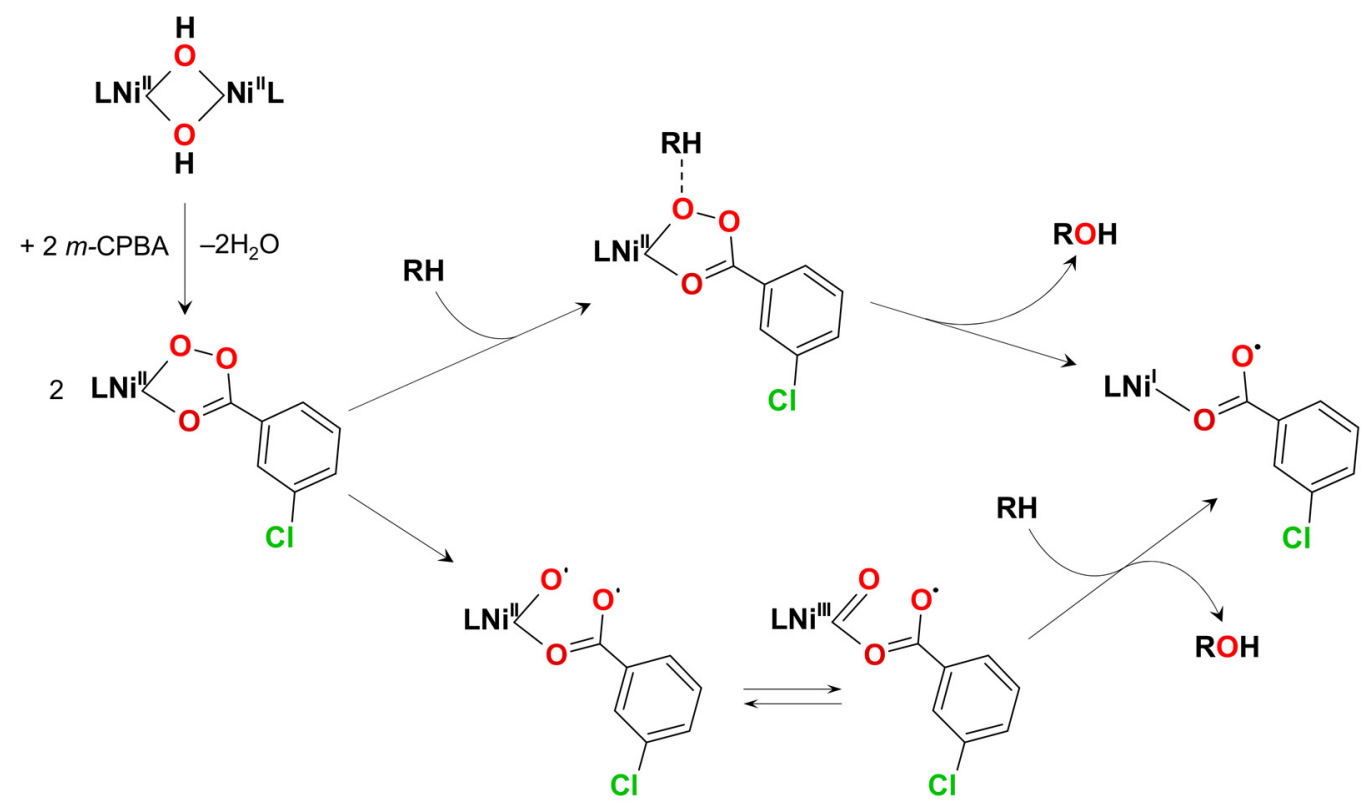

Scheme 7. Proposed reaction pathways for oxidation of the substrate $\mathrm{RH}$ with $m$-CPBA catalyzed by Ni6 [42].

The reaction of $\left[\mathrm{Ni}^{\mathrm{II}}\left(\mathrm{L}^{7 \mathrm{e}}\right)(m-\mathrm{CBA})\right](\mathrm{Ni7})\left(\mathrm{L}^{7 \mathrm{e}}=\right.$ scorpionate ligand $\mathrm{L}^{7}$ (Figure 7, left), where $\mathrm{R}^{1}=\mathrm{CF}_{3}, \mathrm{R}^{2}=\mathrm{H}$ and $\mathrm{R}^{3}=\mathrm{CH}_{3} ; m$-CBA $=m$-chlorobenzoic acid), with two equivalents of $m$-CPBA resulted in the successive conversion of $\mathrm{Ni7}$ to $\left[\mathrm{Ni}^{1 \mathrm{II}}\left(\mathrm{L}^{7 \mathrm{e}}\right)(m-\mathrm{CPBA})\right]$ (Ni7-1), where $m$-CPBA coordinated bidentately with a nickel center (Figure 8) [48]. The compound Ni7-1 is thermally stable, as evidenced by the decomposition rate constant of $1.6 \times 10^{-5} \mathrm{~s}^{-1}$ at $70{ }^{\circ} \mathrm{C}$ in benzene. This remarkable stability allows crystallization and the determination of the structure of Ni7-1 through conventional single crystal X-ray diffraction. The similar complex $\left[\mathrm{Ni}^{\mathrm{II}}\left(\mathrm{L}^{7 \mathrm{a}}\right)(m-\mathrm{CPBA})\right]$, bearing $\mathrm{CH}_{3}$ groups instead of $\mathrm{CF}_{3}$ ones, was unstable even at low temperatures (below $-20^{\circ} \mathrm{C}$ ). The complex Ni7-1 is capable of the direct oxidation of various substrates in toluene medium. Thioanisole was oxidized to the respective sulfoxide with a $96 \%$ yield (Scheme 8) [48]. From the kinetic data, the authors concluded that this oxidation proceeds through the Michaelis-Menten-type mechanism, showing the fast, reversible formation of a substrate-oxidant adduct with subsequent oxidation and oxygen atom transfer. At the elevated temperature of $70{ }^{\circ} \mathrm{C}$ in toluene or trifluorotoluene, Ni7-1 epoxidizes cyclohexene and styrene (Scheme 9) with $66 \%$ and $95 \%$ yields, respectively (based on the oxidant, Ni7-1). Oxidation of substrates having secondary or tertiary sp $\mathrm{s}^{3} \mathrm{C}-\mathrm{H}$ bonds (1,4-cyclohexanediene, 1,10-dihydroanthracene, xanthene (Scheme 9), fluorene and methylcyclohexane) in benzene or toluene was suggested to proceed without cleavage of the $\mathrm{O}-\mathrm{O}$ bond of Ni7-1 (through the concerted mechanism) [48]. Further, the oxidation of methylcyclohexane (Scheme 2) was claimed to proceed with a preference towards the oxidation of secondary $\mathrm{C}-\mathrm{H}$ bonds rather than a tertiary one. This observation was explained by the steric crowding of the tertiary $\mathrm{C}-\mathrm{H}$ bond of methylcyclohexane. However, normalization of the obtained yields of products (taking into account the numbers of $\mathrm{C}-\mathrm{H}$ bonds in the methylcyclohexane molecule) gives rather low $3^{\circ}: 2^{\circ}: 1^{\circ}$ bond selectivity of $8: 2: 1$, where the tertiary $\mathrm{C}-\mathrm{H}$ shows a significant preference over secondary and primary ones. 


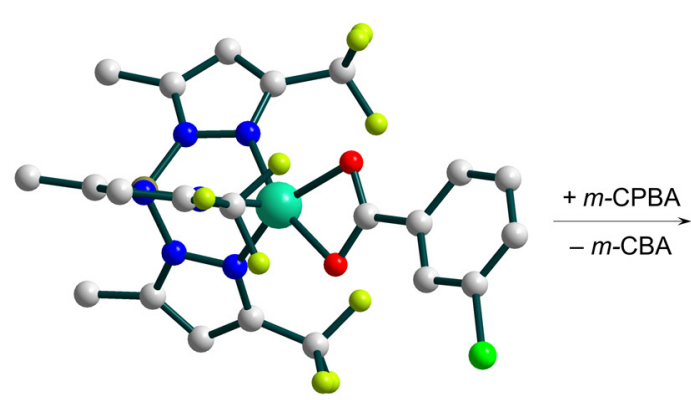

$\mathrm{Ni7}$

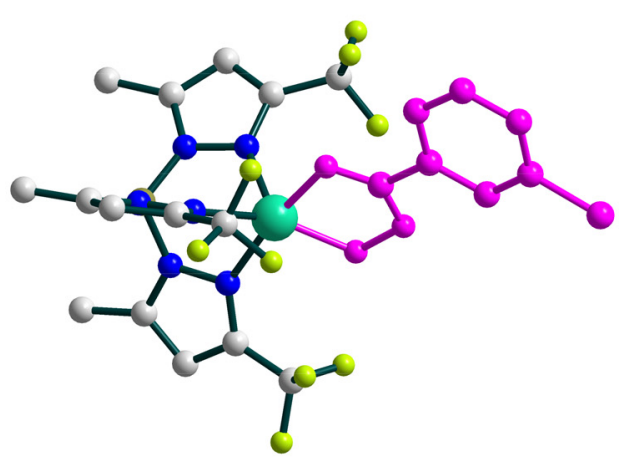

Ni7-1

Figure 8. Molecular structures of the complexes $\left[\mathrm{Ni}^{\mathrm{II}}\left(\mathrm{L}^{7 \mathrm{e}}\right)(m-\mathrm{CBA})\right](\mathrm{Ni7})$ and $\left[\mathrm{Ni}^{\mathrm{II}}\left(\mathrm{L}^{7 \mathrm{e}}\right)(m-\mathrm{CPBA})\right](\mathbf{N i 7}-\mathbf{1})$, where the coordinated $m$-CPBA is highlighted in purple [48]. CSD refcodes TIWMAP and TIWLUI for Ni7 and Ni7-1, respectively. The hydrogen atoms are omitted for clarity. Color scheme: $\mathrm{Ni}$, light green; $\mathrm{O}$, red; N, blue; $\mathrm{Cl}$, green; $\mathrm{F}$, yellow-green; C, grey.<smiles>[X]c1ccc(SC[CH-][NH+]=C=C)cc1</smiles>

Scheme 8. Proposed reaction pathway for stochiometric oxidation of thioanizole with Ni7-1. $\mathrm{X}=\mathrm{Br}, \mathrm{CH}_{3}, \mathrm{OCH}_{3}$.<smiles>[X]c1ccc(C=[N+][In]c2ccccc2)cc1</smiles>

Scheme 9. Stochiometric oxidation of various substrates with $\mathrm{Ni7-1} . \mathrm{X}=\mathrm{Br}, \mathrm{H}, \mathrm{CH}_{3}, \mathrm{OCH}_{3}$.

Direct evidence of the participation of high-valence nickel-oxo species in $\mathrm{Ni} / \mathrm{m}$-CPBA catalytic systems was obtained based on the example of the complex $\left[\mathrm{Ni}^{\mathrm{II}}\left(\mathrm{L}^{8}\right)\right](\mathrm{Ni8})$ with the pincer-like tetradentate 2,6-pyridinecarboxamidate ligand $\mathrm{H}_{2} \mathrm{~L}^{8}$ (Figure 9, left) [49]. The addition of three equivalents of $m$-CPBA to $\mathrm{Ni8}$ at $-30{ }^{\circ} \mathrm{C}$ leads to the formation of the Ni8- $m$-CPBA adduct and the subsequent appearance of $\mathrm{Ni}{ }^{\mathrm{III}}-\mathrm{O} \bullet$ species (Ni8-1) (Figure 9). No chlorobenzene or $\mathrm{CO}_{2}$ were detected by GC-MS analysis, while $m$-chlorobenzoic acid was formed in quantitative amounts, indicating that the heterolytic pathway is dominant (in comparison with the compound Ni5, which exclusively favors homolytic splitting [39]). The structure of Ni8-1 was established by DFT calculations, supported by extended X-ray absorption fine structure (EXAFS) and cryospray ionization mass spectrometry (CSI-MS) spectroscopies. The UV/Vis spectra of Ni8-1 feature the characteristic absorption at $420 \mathrm{~nm}$. The reaction of Ni8-1 with alkenes at $-30^{\circ} \mathrm{C}$ affords epoxides with yields of more than $50 \%$ based on the amount of Ni8. Cyclohexane, ethylbenzene or toluene were oxidized by Ni8-1 to the respective aldehydes and ketones with a $21-47 \%$ yield (based on Ni8), under the same conditions. Control tests confirmed that the background activity of $m$-CPBA under the conditions of the experiment was negligible. Furthermore, the reaction rates exhibited 
by Ni8-1 in the oxidation of methylenic $\mathrm{sp}^{3} \mathrm{C}-\mathrm{H}$ bonds were found to be considerably faster (more than 200 times) than those of Ni5-1/Ni5-2 under the same conditions and ca. three orders faster than that of Ni7-1.<smiles>CN1CCCNC(=O)c2cccc(n2)C(=O)NCC1</smiles>
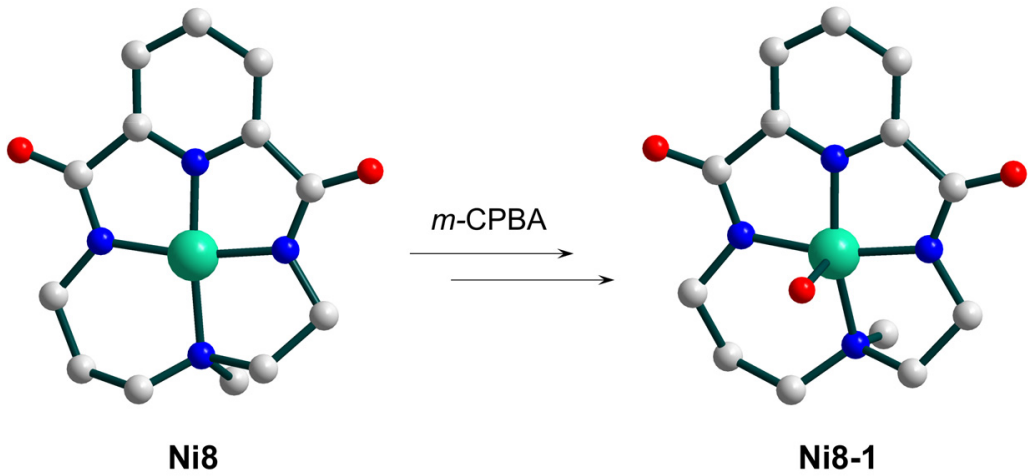

Figure 9. (Left) Schematic representation of the ligand $\mathrm{H}_{2} \mathrm{~L}^{8}$. (Right) Molecular structure of the complex $\left[\mathrm{Ni}^{\mathrm{II}}\left(\mathrm{L}^{8}\right)\right]\left(\mathrm{Ni}^{8}\right)$ (CSD refcode ZEFQOT) and DFT optimized structure of the HVMO derivative $\mathrm{Ni}^{\mathrm{III}} \mathrm{H}$ • (Ni8-1) [49]. Hydrogen atoms are omitted for clarity. Color scheme: Ni, light green; $\mathrm{O}$, red; $\mathrm{N}$, blue; $\mathrm{C}$, grey.

Oxidation of adamantane under other catalytic conditions (150 equivalents of substrate and $m$-CPBA relative to Ni8) proceeded with bond selectivity $3^{\circ}: 2^{\circ}=18: 1$, being very close to that observed for $\mathrm{Ni1}$ and $\mathrm{Ni3}$ catalysts. However, the retention of the stereoconfiguration of cis-1,2-dimethylcyclohexane (Scheme 3) was only at the 84\% level, indicating the possible escape of an alkyl radical with the subsequent epimerization of a stereoconfiguration.

The coordination compound $\left[\mathrm{Ni}^{\mathrm{II}}\left(\mathrm{L}^{9}\right) \mathrm{Cl}\right](\mathbf{N i 9})$ shown in Figure 10 is based on the ligand $\mathrm{HL}^{9}$ (2-[bis(pyridin-2-ylmethyl)amino]-N-(quinolin-8-yl)acetamide) [50]. Complex $\mathrm{Ni9}$ catalyzes the epoxidation of alkenes, with the maximum yield of products up to $72 \%$ (based on the oxidant) and TON of 7 observed for the oxidation of cycloheptene, while trans-2-octene was the least reactive substrate, showing a yield of $36 \%$ (a 10-fold excess of substrate was used). Inversion of the stereoconfiguration was observed in the oxidation of cis-stilbene, which afforded the trans-product in a $24 \%$ yield, while the cis-product was obtained in a $2 \%$ yield only (Scheme 10). The authors explained this effect by the participation of a long-lived radical intermediate in the oxidation route. cis-2-Octene and cishexene revealed a lower degree of inversion, while trans-stilbene was converted exclusively to trans-oxide (along with benzaldehyde and 2-phenylacetophenone by-products). Small amounts $(1-5 \%)$ of chlorobenzene were obtained in all tests, suggesting at least the partial involvement of the homolytic $m$-CPBA cleavage pathway. Epoxidation of cyclohexene in the presence of $\mathrm{H}_{2}{ }^{18} \mathrm{O}$ in a $\mathrm{CH}_{3} \mathrm{CN} / \mathrm{CH}_{2} \mathrm{Cl}_{2}$ medium resulted in $7 \%$ of ${ }^{18} \mathrm{O}$-labeled epoxide. When the same reaction was conducted in $\mathrm{CH}_{3} \mathrm{CN} / \mathrm{CH}_{2} \mathrm{Cl}_{2} / \mathrm{CH}_{3} \mathrm{OH}$ medium $\left(10 \%\right.$ of $\left.\mathrm{CH}_{3} \mathrm{OH}\right)$, the incorporation level was increased to $15 \%$. This fact was interpreted by the authors as evidence of the participation of $\mathrm{Ni}$ (III)-oxo and $\mathrm{Ni}(\mathrm{IV})$-oxo species in the reaction, where the contribution of tetravalent ones, resulted from $m$-CPBA O-O bond heterolysis, increases for a protic solvent. Further evidence of Ni(III) species participation was obtained from EPR spectra of a frozen solution of Ni9 with six equivalents of $m$-CPBA, mixed at $0{ }^{\circ} \mathrm{C}$ (Figure 11), which showed a signal typical for Ni(III). Heating the mixture to room temperature led to the disappearance of the EPR signal, as expected for the $\mathrm{Ni}(\mathrm{III}) \rightarrow$ $\mathrm{Ni}(\mathrm{II})$ reaction (Figure 11). 

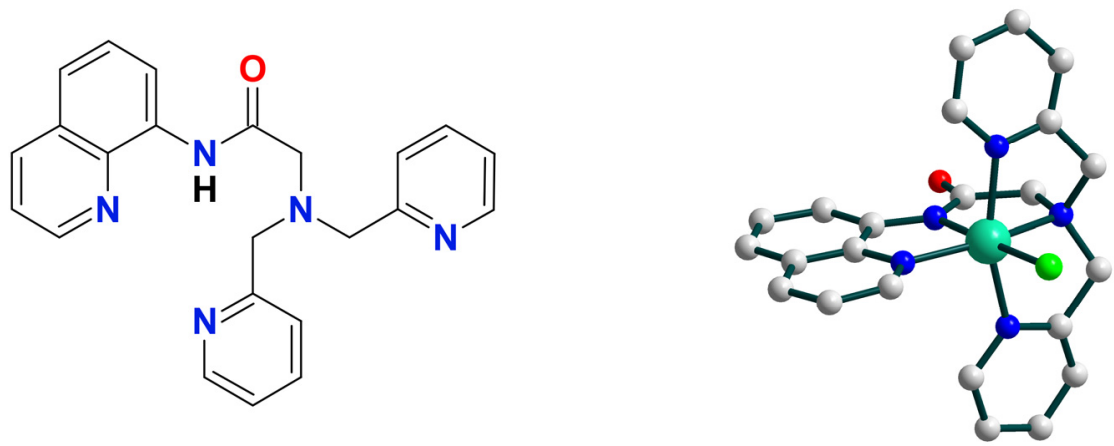

Figure 10. (Left) Schematic representation of the ligand $L^{9}$. (Right) Molecular structure (CSD refcode HATDUE) of the complex $\left[\mathrm{Ni}^{\mathrm{II}}\left(\mathrm{L}^{9}\right) \mathrm{Cl}\right]$ (Ni9) [50]. The hydrogen atoms are omitted for clarity. Color scheme: $\mathrm{Ni}$, light green; $\mathrm{O}$, red; $\mathrm{N}$, blue; $\mathrm{Cl}$, green; $\mathrm{C}$, grey.<smiles>C(=C\c1ccccc1)\c1ccccc1</smiles>

cis-stilbene<smiles>c1ccc(C2OC2c2ccccc2)cc1</smiles>

trans-stilbene oxide<smiles></smiles><smiles>[R]C([CH]C)[C@H]([R])O[NH-]</smiles><smiles>[R][C]([R])[C@H]([2H])O[NH-]</smiles><smiles>[R]C1O[C@H]1[R]</smiles>

Scheme 10. (Top) Oxidation of cis-stilbene with $m$-CPBA, catalyzed by the complex Ni9, affording the trans-epoxide as the main product. (Bottom) Proposed cis/trans isomerization mechanism [50].
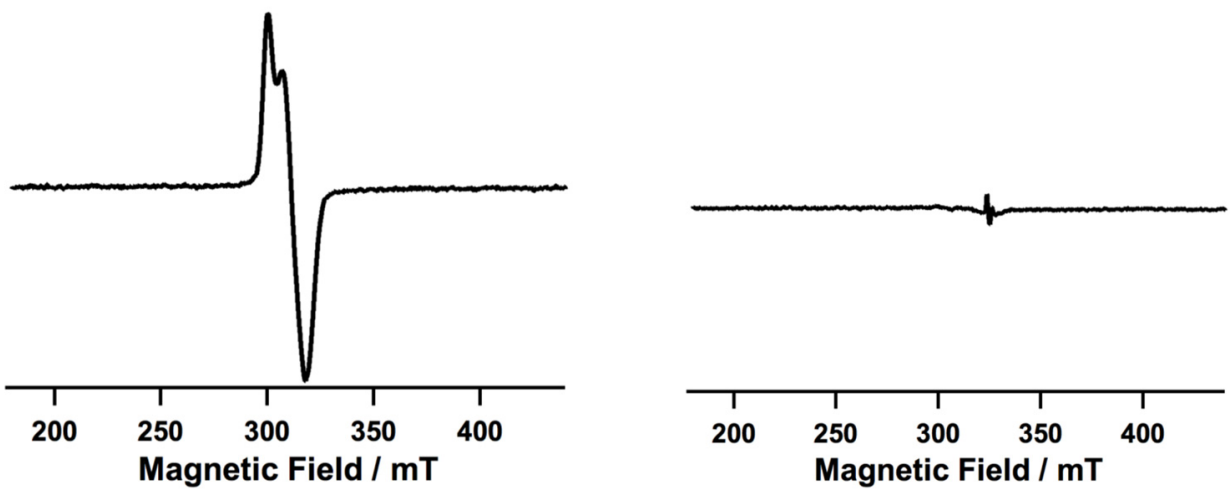

Figure 11. (Left) The EPR spectrum of the Ni(III) species formed upon treatment of the complex Ni9 with $m$-CPBA (recorded at $113 \mathrm{~K}$ ). (Right) Decay of the spectrum when heated to room temperature. Adapted with permission from [50], Wiley, 2017.

The catalytic activity of the azide-containing complex $\left[\mathrm{Ni}\left(\mathrm{H}_{3} \mathrm{~L}^{10}\right)\left(\mathrm{N}_{3}\right)_{2}\right]_{2}(\mathrm{Ni10})$ bearing the polydentate $\mathrm{N}, \mathrm{O}$-donor ligand $\left(\mathrm{H}_{3} \mathrm{~L}^{10}=\mathrm{N}\right.$-(2-pyridylmethyl)- $\mathrm{N}^{\prime}$-(2-hydroxyethyl)ethylenediamine) (Figure 12) was studied using 2.8-fold excess of $m$-CPBA over the substrate (in contrast to Ni9: $m-\mathrm{CPBA}=1: 1$ ratio discussed above) [51]. Under these conditions, quantitative conversions of alkene substrates were achieved, with average selectivity towards epoxides of ca. 70\%. The catalytic system Ni10/m-CPBA was quite efficient towards the epoxidation of vinylcyclohexane $\left(87 \%\right.$ conversion in $\mathrm{CH}_{3} \mathrm{CN} / \mathrm{CH}_{2} \mathrm{Cl}_{2}$ media) as well as 
terminal olefines (89-100\% conversion) (Scheme 11), known to be less reactive due to their electron-deficient nature. Moreover, the catalytic system Ni10/m-CPBA revealed distinct selectivity towards the trans-epoxides. Both cis- and trans-stilbene oxidation resulted in trans-epoxide with $65 \%$ yield, showing less than $10 \%$ of cis-epoxide. Such behavior is similar to that observed for the catalyst Ni9 (Scheme 10). The blank test in the absence of a catalyst revealed a $10 \%$ yield of products, while $\mathrm{NiCl}_{2}$ or $\mathrm{Ni}\left(\mathrm{NO}_{3}\right)_{2}$ did not catalyze the reaction at all. The appearance of $5 \%$ of ${ }^{18} \mathrm{O}$-labeled epoxide from $\mathrm{H}_{2}{ }^{18} \mathrm{O}$ in the course of cyclohexene oxidation was considered by the authors as evidence for high-valence nickel-oxo species, as the latter may exchange oxygen with water. Mixing the complex Ni10 with six equivalents of $m-\mathrm{CPBA}$ at $-40{ }^{\circ} \mathrm{C}$ in $\mathrm{CH}_{3} \mathrm{CN} / \mathrm{CH}_{2} \mathrm{Cl}_{2}$ afforded a red solution with broad absorption at $500 \mathrm{~nm}$, presumably constituting a high-valence nickel intermediate, Ni10-1. The EPR spectrum of Ni10-1 revealed a rhombic signal, typical for nickel(III) species (Figure 13). The authors proposed $\mathrm{Ni}(\mathrm{IV})=\mathrm{O}$ species as those responsible for the olefin epoxidations, while $\mathrm{Ni}(\mathrm{III})=\mathrm{O}$ ones were presumed to promote less selective allylic C-H oxidation [51].
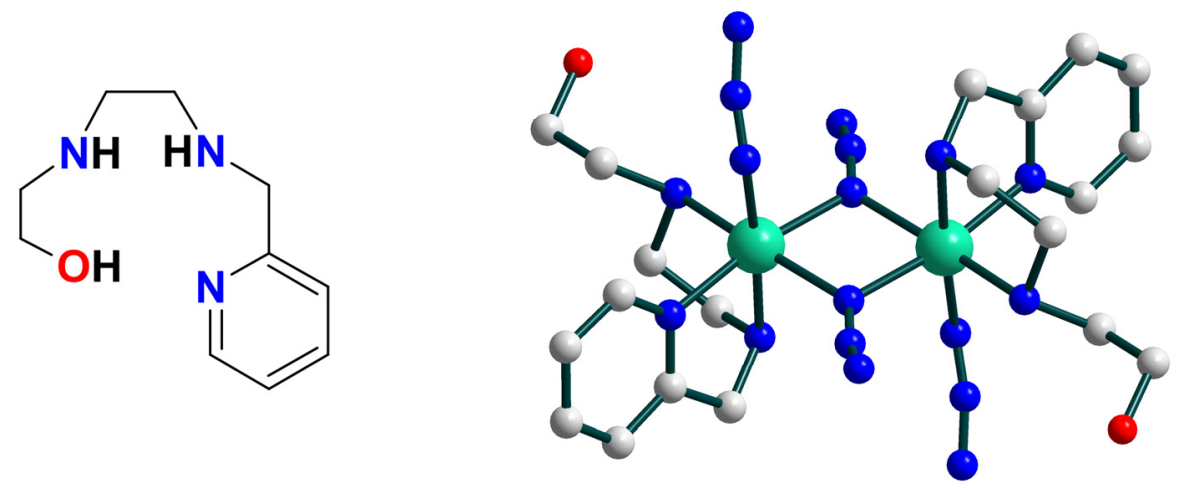

Figure 12. (Left) Schematic representation of the ligand $\mathrm{H}_{3} \mathrm{~L}^{10}$. (Right) Molecular structure (CSD refcode HARSUR) of the complex $\left[\mathrm{Ni}^{\mathrm{II}}\left(\mathrm{H}_{3} \mathrm{~L}^{10}\right)\left(\mathrm{N}_{3}\right)_{2}\right]_{2}$ (Ni10) [51]. The hydrogen atoms are omitted for clarity. Color scheme: $\mathrm{Ni}$, light green; $\mathrm{O}$, red; $\mathrm{N}$, blue; $\mathrm{C}$, grey.

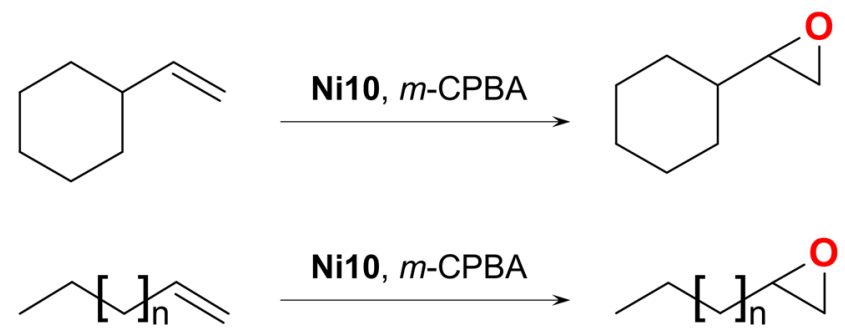

Scheme 11. Epoxidation of vinylcyclohexane and terminal olefins $(n=2,4-12,14)$ with $m$-CPBA, catalyzed by $\mathbf{N i 1 0}[51]$.
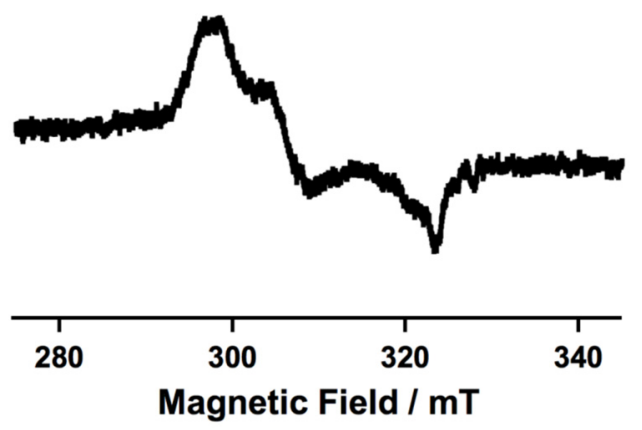

Figure 13. The EPR spectrum of the Ni(III) species formed upon treatment of the complex Ni10 with m-CPBA, recorded at $100 \mathrm{~K}$. Reproduced with permission from [51], Wiley, 2017. 
The catalytic system Ni10/PPAA (where PPAA = phenylperacetic acid) was used to evaluate the contribution of homolytic $\mathrm{O}-\mathrm{O}$ bond splitting to the overall reaction mechanism by monitoring the toluene formation, which appears from the decarboxylation of the $\mathrm{PhCH}_{2} \mathrm{C}(\mathrm{O}) \mathrm{O} \bullet$ radical. From the observed yields of toluene (50\%), the contribution of PPAA homolysis can be considered rather high. This observation raises the question of whether the attacking species are nickel HVMO species or oxyl radicals $\mathrm{PhCH}_{2} \mathrm{C}(\mathrm{O}) \mathrm{O} \bullet$ or $\mathrm{ArC}(\mathrm{O}) \mathrm{O} \bullet$ (for PPAA and m-CPBA catalytic systems, respectively) because the O-centered carboxyl radicals, as well as their decarboxylation products, $\mathrm{PhCH}_{2} \bullet$ and Ar• ones, respectively, are capable of $\mathrm{H}$ atom abstraction from $\mathrm{C}-\mathrm{H}$ bonds as well as the epoxidation of olefins.

A similar investigation of epoxidation catalytic activity was performed for the substituted porphyrin complex $\left[\mathrm{Ni}^{\mathrm{iI}}\left(\mathrm{L}^{11}\right)\right]$ (Ni11) (where $\mathrm{H}_{2} \mathrm{~L}^{11}=5,10,15,20$-tetrakis[2,6-di $(n$ butoxy)phenyl]porphyrin) [52]. In contrast to the catalyst Ni10, oxidation of cis-2-octene catalyzed by $\mathbf{N i 1 1}$ resulted in cis-epoxide as the main product, while the stereoconfiguration of cis-stilbene was epimerized, showing nearly equal amounts of cis- and trans-epoxides. The catalyst Ni11 showed a lower contribution of homolytic O-O splitting, as evidenced by the tests using PPAA oxidant (where the percentage of homolytic splitting was estimated from the sum of the amounts of benzaldehyde, benzyl alcohol and toluene). The highest percentage of the homolytic mechanism in the epoxidation of cyclohexene $(27 \%)$ was observed for the protic media $\left(\mathrm{CH}_{3} \mathrm{CN} / \mathrm{H}_{2} \mathrm{O}\right)$ and polar aprotic media $\left(\mathrm{CH}_{3} \mathrm{CN}\right)$, while the less polar aprotic solvents $\left(\mathrm{CH}_{2} \mathrm{Cl}_{2}\right.$ or toluene) resulted in the homolysis contribution ranging from 4 to $24 \%$. The participation of $\mathrm{Ni}(\mathrm{II})-\mathrm{OOC}(\mathrm{O}) \mathrm{R}, \mathrm{Ni}(\mathrm{III})$ and $\mathrm{Ni}(\mathrm{IV})$ oxo intermediates was proposed, depending on the nature of the solvent. The incorporation of ${ }^{18} \mathrm{O}$ into the cyclohexene oxide from $\mathrm{H}_{2}{ }^{18} \mathrm{O}$ was at the $5 \%$ level, suggesting the participation of HVMO species as key oxidation intermediates. However, since the enrichment level is low, the results of such ${ }^{18} \mathrm{O}$-labeling studies should be treated cautiously. For example, oxidation of trans-decahydronaphthalene with $m$-CPBA, catalyzed by phthalocyanine complexes $\left[\mathrm{M}^{\mathrm{II}}(\mathrm{pc})\right](\mathrm{M}=\mathrm{Fe}, \mathrm{Ni}$ and $\mathrm{Co})$ in the presence of $\mathrm{H}_{2}{ }^{18} \mathrm{O}$ and a nitric acid promoter, afforded nearly equal ${ }^{18} \mathrm{O}$ incorporation levels of $3 \%$ into the alcohols [53]. Since the stabilities and lifetimes of iron, nickel and cobalt HVMO species drastically decrease in this order [54,55] (the so-called "oxo wall" [55]), it is unlikely that the rates of oxygen exchange would increase at the same magnitude, leading to the same ${ }^{18} \mathrm{O}$-enrichment in all cases. Hence, the most plausible explanation is the existence of some other mechanism of the ${ }^{18} \mathrm{O}$-incorporation (apart from the direct exchange between the product and water, which is usually excluded), while the ${ }^{18} \mathrm{O}$ tests in the above studies could not serve as clear evidence for the presence of HVMO intermediates.

A series of mononuclear complexes with oxazoline-containing tertiary amine ligand $\mathrm{L}^{12}$ (Figure 14, left), differing by coordinated anions $\left[\mathrm{Ni}^{\mathrm{II}}\left(\mathrm{L}^{12}\right) \mathrm{X}\right]\left(\mathrm{BPh}_{4}\right)(\mathrm{X}=\mathrm{Cl}, \mathrm{OAc}$, $\left.\mathrm{NO}_{3}, m-\mathrm{CBA}\right)$, was synthesized and tested towards catalytic alkane oxidation with $m$ CPBA [56]. The most active complex of this series, $\left[\mathrm{Ni}^{\mathrm{II}}\left(\mathrm{L}^{12}\right) \mathrm{Cl}\right]\left(\mathrm{BPh}_{4}\right)(\mathrm{Ni12})$ (Figure 14, right), catalyzed the oxidation of methylcyclohexane, with an overall TON of 54 and $3^{\circ}: 2^{\circ}$ bond selectivity of 9:1 (the amounts of $1^{\circ}$ products were negligible). The respective bond selectivity for adamantane was 19:1 for Ni12 (ranging from 16:1 to 19:1 for this series of complexes). Oxidation of cyclohexane was conducted using a ten-times higher amount of $m$-CPBA (0.13 equivalents relative to substrate), allowing TONs of up to 974 to be obtained (for Ni12). The amount of chlorobenzene by-product was comparable to that for cyclohexanol, which is unambiguous evidence of $m$-CPBA homolysis as the main reaction route. Substantial amounts of $\varepsilon$-caprolactone and chlorocyclohexane (Scheme 4) were observed (the ratio cyclohexanol:cyclohexanone: $\varepsilon$-caprolactone:chlorocyclohexane was 127:14:1:7); the origin of chlorine (m-CPBA or $\mathrm{CH}_{2} \mathrm{Cl}_{2}$ from the solvent mixture) was not discussed. In general, the nature of anion $\mathrm{X}$ in the $\left[\mathrm{Ni}^{\mathrm{II}}\left(\mathrm{L}^{12}\right) \mathrm{X}\right]\left(\mathrm{BPh}_{4}\right)$ catalysts did not greatly influence the yields of products or bond selectivity. The complexes bearing $m$-CBA and, especially, the $\mathrm{NO}_{3}$ anion revealed significant induction periods, which could be associated with stronger binding of the respective anions to the nickel centers. The 
kinetic isotope effect in the parallel oxidation of normal and $d_{12}$-deuterated cyclohexane was found to be 2.67 for the acetate complex $\left[\mathrm{Ni}^{\mathrm{II}^{\mathrm{II}}}\left(\mathrm{L}^{12}\right)(\mathrm{OAc})\right]\left(\mathrm{BPh}_{4}\right)(\mathbf{N i 1 2 a})$ as catalyst. Oxidation of toluene catalyzed by the latter compound resulted in bibenzyl as one of the main reaction products (Scheme 12). Bibenzyl appears from the coupling of two long-lived benzyl radicals and, therefore, the catalytic system operates via a free radical mechanism. Such an observation suggests [57] that the catalyst Ni12a does not interfere with this mechanism and does not act as a trap for carbon-centered radicals [56]. CSI-MS and UV spectroscopies were employed to trap the reactive intermediates. Mixing of Ni12a with $m$ $\mathrm{CPBA}$ in $\mathrm{CH}_{2} \mathrm{Cl}_{2}$ immediately resulted in the formation of the adduct $\left[\mathrm{Ni}^{\mathrm{II}}\left(\mathrm{L}^{12}\right)(m-\mathrm{CPBA})\right]^{+}$ with an absorption band at $398 \mathrm{~nm}$, which disappeared within one day.
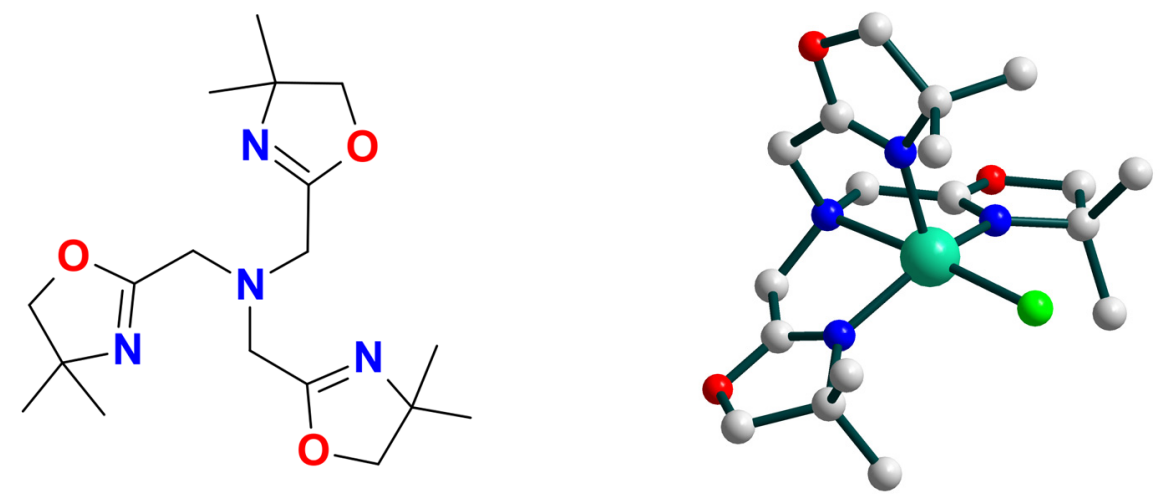

Figure 14. (Left) Schematic representation of the ligand $\mathrm{H}_{3} \mathrm{~L}^{12}$. (Right) Molecular structure (CSD refcode HUPLIQ) of the complex [ $\left.\mathrm{Ni}^{\mathrm{II}}\left(\mathrm{L}^{12}\right) \mathrm{Cl}\right]\left(\mathrm{BPh}_{4}\right)(\mathrm{Ni12})$ [56]. The hydrogen atoms and $\mathrm{BPh}_{4}$ anion are omitted for clarity. Color scheme: $\mathrm{Ni}$, light green; $\mathrm{O}$, red; $\mathrm{N}$, blue; $\mathrm{Cl}$, green; $\mathrm{C}$, grey.<smiles>Cc1ccccc1</smiles>

\section{Ni12a, $m$-CPBA}

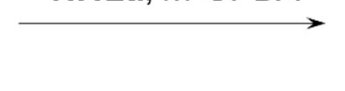<smiles>c1ccc(CCc2ccccc2)cc1</smiles><smiles>OCc1ccccc1</smiles><smiles>O=Cc1ccccc1</smiles>

Scheme 12. Oxidation of toluene with $m$-CPBA, catalyzed by Ni12a, with formation of bibenzyl as a main product [56].

The coordination compounds of nickel with rigid N- or N,O-donor ligands (terpyridine, bisoxazoline, substituted phenanthrolines and bipyridines) was applied for the catalytic hydroxylation of polyethylene with $m$-CPBA [58]. The model substrates comprised cyclohexane and $n$-octadecane. Despite the structural similarity, all the catalysts revealed a broad range of turnover numbers in the oxidation of cyclohexane (Scheme 4$)$. The lowest efficiency $(\mathrm{TON}=60$ ) was found for $\left[\mathrm{Ni}^{\mathrm{II}}\left(\mathrm{L}^{13 \mathrm{db}}\right)_{2}(\mathrm{OAc})\right]\left(\mathrm{BPh}_{4}\right)$, where $\mathrm{L}^{13 \mathrm{db}}=2,9$-dimethylphenanthlorine (Figure 15). The complex bearing the terpyridine ligand $\left[\mathrm{Ni}^{\mathrm{II}}\left(\mathrm{L}^{13 \mathrm{~b}}\right)_{3}\right]\left(\mathrm{BPh}_{4}\right)_{2}$ was the least reactive $(\mathrm{TON}=132)$ from the $\mathrm{M}(\mathrm{L})_{3}$ family. The highest turnover number of 5560 in cyclohexane oxidation, supported by the yield of cyclohexanol of $52 \%$, was observed for $\left[\mathrm{Ni}^{\mathrm{II}}\left(\mathrm{L}^{13 \mathrm{dc}}\right)_{3}\right]\left(\mathrm{BPh}_{4}\right)_{2}$ (Ni13) (Figure 15) [58]. Then, the catalyst Ni13 was tested towards the hydroxylation of $n$-octadecane at an elevated temperature of $80{ }^{\circ} \mathrm{C}$ (Scheme 13) to confirm the conditions required further for the polyethylene oxidation, since the latter is hardly soluble below this temperature. Using four equivalents of $m$-CPBA relative to $n$-octadecane and a catalyst loading of $0.4 \mathrm{~mol} \%$, $n$-octadecanol was obtained as the main reaction product (yield of $41 \%$ relative to the substrate), while the amount of ketone was two-times lower (21\%). Significant amounts ( $20 \%$ of yield) of the chloro-derivative of $n$-octadecane were also detected. The dichloroethane solvent was shown to be the main source of chlorine. However, both $m$-CPBA and chlorobenzene could also serve as chlorine sources, as was demonstrated by the comparative tests. Oxidation of low-molecular-weight polyethylene $(4.3 \mathrm{~kg} / \mathrm{mol})$ under 
similar conditions using the catalyst Ni13 resulted in the maximum degree of polyethylene functionalization of 5.5 (sum of all functionalized products) per 100 monomers, with selectivity towards alcohols of up to $88 \%$. Functionalization of a high-molecular-weight polyethylene required the addition of 1,2,4-trichlorobenzene as a co-solvent, an increase in the reaction temperature up to $90^{\circ} \mathrm{C}$ and a decrease in the substrate concentration. Notably, in the absence of a nickel catalyst, the molecular weight parameters of the functionalized polymers were considerably lower than those for nickel-catalyzed reactions, indicating the cleavage of the polyethylene chain under the catalyst-free conditions.

$L^{13 a}$<smiles>CC(C)(C1=NCCO1)C1=NCCO1</smiles><smiles>c1ccc(-c2cccc(-c3ccccn3)n2)nc1</smiles><smiles>[R]c1ccnc(-c2cc([R])ccn2)c1</smiles>

$L^{13 d}$<smiles></smiles>

\begin{tabular}{c|cccc} 
& $\mathrm{R}^{1}$ & $\mathrm{R}^{2}$ & $\mathrm{R}^{3}$ & $\mathrm{R}^{4}$ \\
\hline $\mathrm{L}^{13 \mathrm{ca}}$ & $\mathrm{H}$ & - & - & - \\
$\mathrm{L}^{13 \mathrm{cb}}$ & $\mathrm{tBu}$ & - & - & - \\
$\mathrm{L}^{13 \mathrm{da}}$ & - & $\mathrm{H}$ & $\mathrm{H}$ & $\mathrm{H}$ \\
$\mathrm{L}^{13 \mathrm{db}}$ & - & $\mathrm{CH}_{3}$ & $\mathrm{H}$ & $\mathrm{H}$ \\
$\mathrm{L}^{13 \mathrm{dc}}$ & - & $\mathrm{H}$ & $\mathrm{Me}$ & $\mathrm{Me}$
\end{tabular}

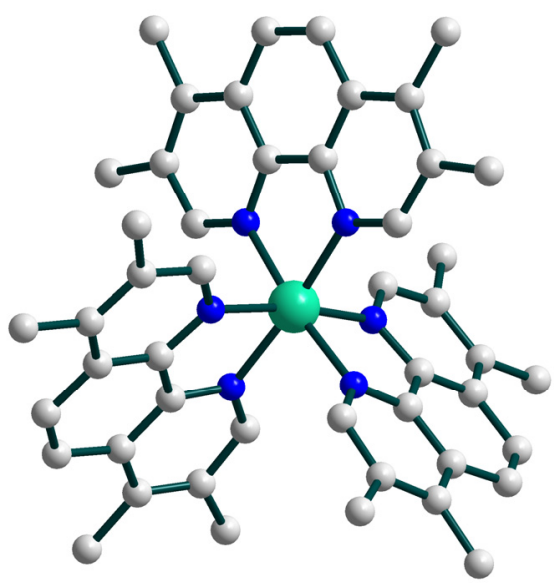

Figure 15. (Left) Schematic representation of the ligand family $\mathrm{L}^{13}$. (Right) Molecular structure (CSD refcode CEHWOE) of the complex $\left[\mathrm{Ni}^{\mathrm{II}}\left(\mathrm{L}^{13 \mathrm{dc}}\right)_{3}\right]\left(\mathrm{BPh}_{4}\right)_{2}$ (Ni13) [58]. The hydrogen atoms and $\mathrm{BPh}_{4}$ anion are omitted for clarity. Color scheme: $\mathrm{Ni}$, light green; $\mathrm{N}$, blue; $\mathrm{C}$, grey.

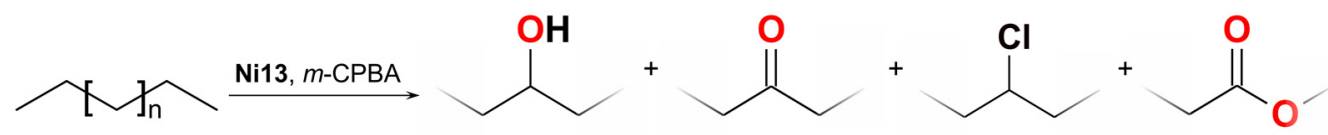

Scheme 13. Oxidation of $n$-octadecane $(n=14)$ and polyethylene $\left(M_{\mathrm{w}}\right.$ ranges from 4.3 to $\left.122.9 \mathrm{~kg} \mathrm{~mol}{ }^{-1}\right)$ with $m$-CPBA, catalyzed by Ni13 [58].

The chiral oxazoline-based compounds $\mathrm{L}^{14}$ (Scheme 14) were recently explored as ligands for nickel catalysts in $\mathrm{C}-\mathrm{H}$ oxidation with $m$-CPBA [59]. This family of ligands has recognized applications in asymmetric catalysis due to the possibility of the introduction of various bulky groups in a chiral manner into their structure. Only one complex of this series was isolated, $\left[\mathrm{Ni}\left(\mathrm{L}^{14 \mathrm{bc}}-\mathrm{H}\right)_{2}\right](\mathrm{Ni14})$ (Figure 16$)$, where the ligand $\mathrm{L}^{14 \mathrm{bc}}$ was converted into the $\beta$-diketiminate form [59]. The complexes with the other ligands $\left(\mathrm{L}^{14 a}, \mathrm{~L}^{14 \mathrm{ba}-\mathrm{bb}}\right.$ and $\mathrm{L}^{14 \mathrm{bd}}$ ) were not isolated and were used for catalysis in situ, where the catalyst was formed through the reaction of $\mathrm{Ni}(\mathrm{OAc})_{2}$ with one equiv. of the respective ligand. Oxidation of cyclohexane (Scheme 4) afforded cyclohexanol as the main product in all cases. The highest activity (TON of 651 and yield of products of $65 \%$ relative to $m$-CPBA, which was in deficiency) was observed for the ligand $\mathrm{L}^{14 \mathrm{ba}}$ for the reaction performed under an inert atmosphere. Large amounts of chlorobenzene (31\% relative to $m$-CPBA) were detected. The presence of air caused a decrease in the overall TON down to 322 and, at the same time, a decrease in the amounts of chlorobenzene down to $10 \%$. The same behavior was observed for all in situ-formed catalysts in this series as well as the isolated compound Ni14. Oxidation of methylcyclohexane afforded $3^{\circ}: 2^{\circ}$ bond selectivity ranging from $6: 1$ to 8:1 (the latter ratio was observed for Ni14). The use of nickel acetate as a catalyst resulted in 9:1 bond selectivity under the same conditions. Although the observed normalized bond selectivity unequivocally indicates the high activity of the catalytic systems towards the oxidation of tertiary $\mathrm{C}-\mathrm{H}$ bonds, the authors suggested that the higher absolute amounts of secondary products may be due to the reduced hindrance of the secondary groups as 
compared to the tertiary ones [59]. A plausible metal-mediated reaction mechanism similar to that depicted in Scheme 5 was proposed, where the $\mathrm{Ni}(\mathrm{I})$ species undergo oxidation with air oxygen. The $\operatorname{ArC}(\mathrm{O}) \mathrm{O} \bullet$ and Ar• radicals formed during this reaction (Scheme 1) were presumed to react with an alkane. Very large amounts of chlorobenzene product, comparable to those for alcohols, highlight the high contribution of a free radical pathway to the overall mechanism and free radicals as $\mathrm{C}-\mathrm{H}$ attacking species. The overall activity and selectivity parameters only weakly depended on the ligand's nature. Therefore, the $\mathrm{O}$ - and $\mathrm{C}$-centered radicals formed from $m$-CPBA are likely the $\mathrm{C}-\mathrm{H}$ attacking species in these catalytic systems. Unfortunately, no test for the presence of alkyl hydroperoxide was performed (nor through the direct detection nor by using the $\mathrm{PPh}_{3}$ reductant); thus, it is not possible to evaluate the contribution of this compound, which is a typical product in free radical alkane oxidation.<smiles>c1ccc([C@H]2COC(c3cccc(C4=N[C@@H](c5ccccc5)CO4)n3)=N2)cc1</smiles>

$\mathrm{L}^{14 a}$<smiles>[R]C1=NC(C([R])([R])C2=NC([R])C([R])O2)=NC1[R]</smiles>

$L^{14 b}$

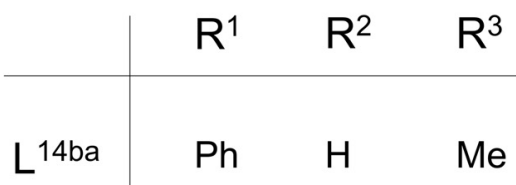

$\llcorner 14 b b$

$\mathrm{Ph} \quad \mathrm{Ph} \quad \mathrm{Me}$

$\mathrm{L}^{14 b c} \quad \mathrm{Ph} \quad \mathrm{Ph} \quad \mathrm{H}$

$\begin{array}{llll}\mathrm{L}^{14 b d} & i \mathrm{Pr} & \mathrm{H} & \mathrm{Me}\end{array}$

Scheme 14. Schematic representation of the ligand family $\mathrm{L}^{14}[59]$.<smiles>c1ccc([C@@H]2N=C(CC3=N[C@H](c4ccccc4)[C@@H](c4ccccc4)O3)O[C@@H]2c2ccccc2)cc1</smiles>

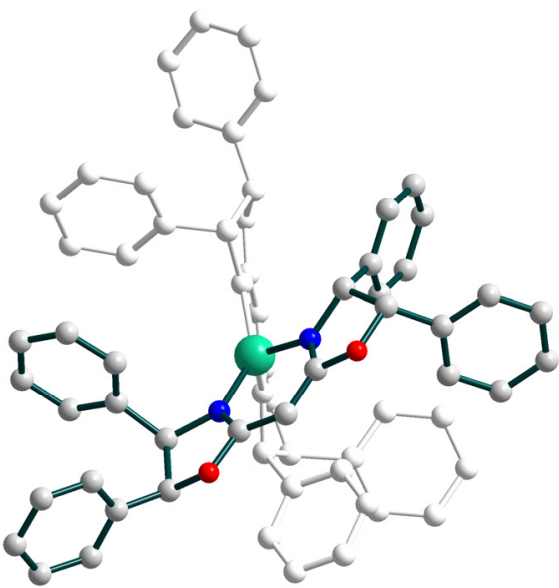

Figure 16. (Left) Schematic representation of the ligand $\mathrm{L}^{14 \mathrm{bc}}-\mathrm{H}$. (Right) Molecular structure (no CSD refcode available for the moment) of the complex $\left[\mathrm{Ni}^{\mathrm{II}}\left(\mathrm{L}^{14 \mathrm{bc}}-\mathrm{H}\right)_{2}\right](\mathrm{Ni14})$ [59]. The hydrogen atoms are omitted. One of the coordinated ligands is shown in bleached form, for clarity. Color scheme: $\mathrm{Ni}$, light green; $\mathrm{O}$, red; $\mathrm{N}$, blue; $\mathrm{C}$, grey.

The presence of the chiral ligands $\mathrm{L}^{14}$ could lead to asymmetric hydroxylation in the event that the metal complex intermediate is a $\mathrm{C}-\mathrm{H}$ attacking species. The in situformed nickel complexes with the ligands $\mathrm{L}^{14 \mathrm{a}}, \mathrm{L}^{14 \mathrm{ba}}$ and $\mathrm{L}^{14 \mathrm{bc}}$ were tested as catalysts for ethylbenzene oxidation (Scheme 15). $R$ - and S-2-phenylethanols were formed in a nearly 1:1 ratio, which is reflected by the negligible (ca. 1\%) enantioenrichment (ee) value. The formation of a racemic mixture of products is expected if the $\mathrm{H}$ atoms are abstracted by a small organic radical rather than a bulky nickel-oxo or nickel-peroxide complex. 


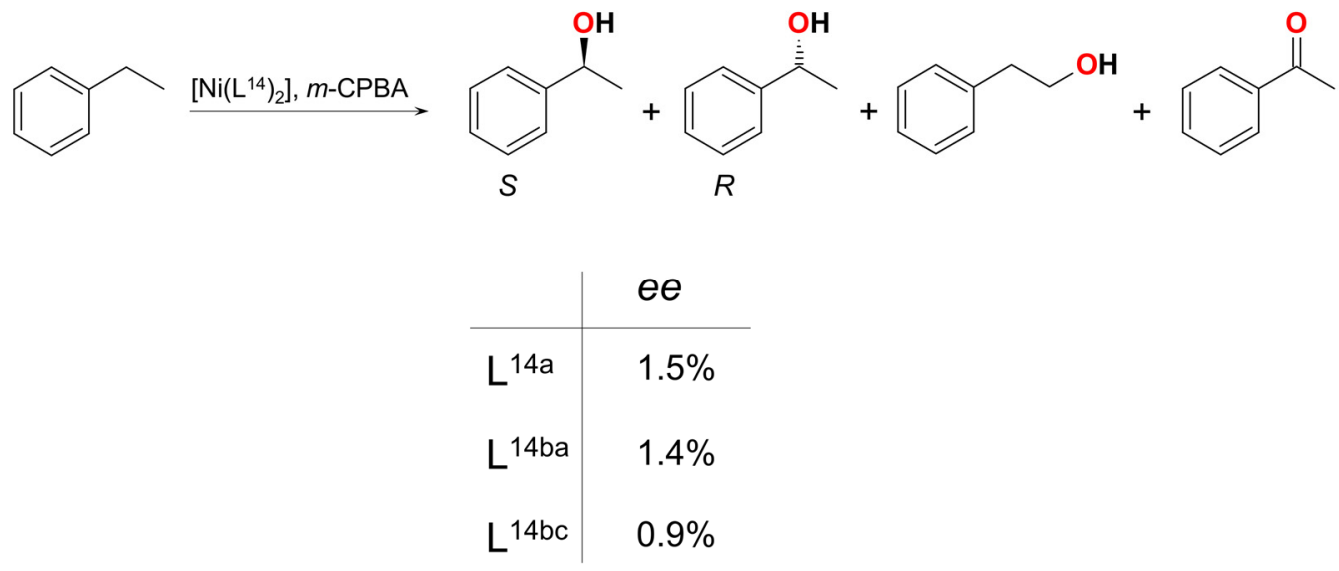

Scheme 15. Oxidation of ethylbenzene with $m$-CPBA, catalyzed by selected complexes of the ligand family $\mathrm{L}^{14}$. ee means enantioenrichment, calculated as $(S-R) /(S+R) \times 100$, where $S$ and $R$ are concentrations of the respective enantioentiomers of 1-phenylethanol.

The largest coordination compound of nickel, tested as a catalyst for this type of reaction, is the complex with silsesquioxane ligand $\left[\mathrm{Ni}_{6}{ }_{6} \mathrm{Cl}\left(\mathrm{L}^{15 \mathrm{a}}\right)_{2}\left(\mathrm{~L}^{15 b}\right)_{2} \text { (diox)](Na)(diox }\right)_{13}\left(\mathrm{H}_{2} \mathrm{O}\right)_{2}$ (Ni15) (where $\left(\mathrm{L}^{15 \mathrm{a}}\right)^{6-}=$ macrocyclic silsesquioxane anion formed in situ; $\mathrm{L}^{15 \mathrm{~b}}=$ benzonitrile; diox = dioxane) (Figure 17) [60]. The compound features a planar hexanuclear Ni(II) core of the $\left[\mathrm{M}_{6}(\mu-\mathrm{X})_{12}\right]$ molecular structure type. The complex was studied as a catalyst for the oxidation of alkanes with various oxidants, including $m$-CPBA. Cyclohexane was oxidized at a $24 \%$ yield (sum of cyclohexanol and cyclohexanone), supported by a TON of 64 and TOF of $256 \mathrm{~h}^{-1}$. Oxidation of methylcyclohexane gave a mixture of products, with a total yield of $9 \%$. Although the bond selectivity was not reported, the authors noted that the product ratio was different from those observed for TBHP and $\mathrm{H}_{2} \mathrm{O}_{2}$ oxidants. More importantly, the oxidation of cis-1,2-dimethylcyclohexane produced both cis- and trans-tertiary alcohols, providing strong evidence of the participation of free alkyl radicals within the catalytic cycle.
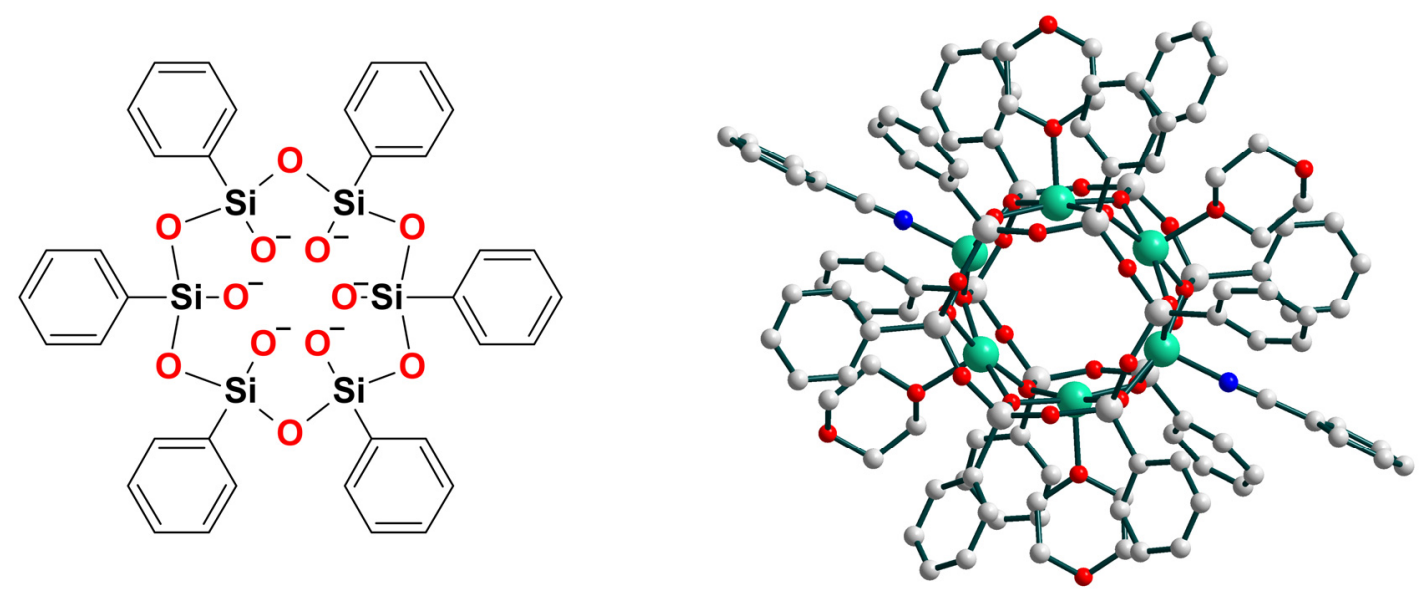

Figure 17. (Left) Schematic representation of the in situ-formed ligand $\left(\mathrm{L}^{15 a}\right)^{6-}$. (Right) Molecular structure (no CSD refcode available for the moment) of the complex $\left[\mathrm{Ni}_{6}{ }_{6} \mathrm{Cl}\left(\mathrm{L}^{15 \mathrm{a}}\right)_{2}\left(\mathrm{~L}^{15 \mathrm{~b}}\right)_{2}(\operatorname{diox})\right](\mathrm{Na})(\operatorname{diox})_{13}\left(\mathrm{H}_{2} \mathrm{O}\right)_{2}(\mathrm{Ni15})$. The uncoordinated anions and cations, as well as solvents and hydrogen atoms, are omitted for clarity. Color scheme: Ni, light green; $\mathrm{O}$, red; N, blue; Si and C, grey.

As can be seen from Table 1, most of the catalysts Ni1-Ni15 were proposed to oxidize $\mathrm{C}-\mathrm{H}$ bonds by nickel-oxo species, mostly $\mathrm{Ni}^{\mathrm{II}}-\mathrm{O} \bullet$ or $\mathrm{Ni}^{\mathrm{III}}=\mathrm{O}$ ones. While the formation of $\mathrm{Ni}(\mathrm{III})$ intermediates during oxidation with $m$-CPBA was confirmed by EPR (Ni5, Ni9 and Ni10) and EXAFS (Ni8) spectroscopies as well as DFT calculations (Ni4 and Ni8), the question of whether these species are in fact those attacking and breaking the $\mathrm{C}-\mathrm{H}$ 
bonds of the substrates remains open. The main concern is that the bond selectivities are roughly the same for catalysts bearing different ligands. Furthermore, most of the catalysts induce homolytic splitting of $m$-CPBA (as evidenced by large amounts of a chlorobenzene product), inevitably generating a series of $\mathrm{O}$ - and $\mathrm{C}$-centered radicals. Therefore, there is a possibility that the metal complex catalyst and its high-valence intermediate act merely as activators of the oxidant, $m$-CPBA, generating other species (presumably O-centered radicals), which, in fact, are $\mathrm{C}-\mathrm{H}$ attacking ones.

A series of nickel complexes with $\mathrm{L}^{13}$ and $\mathrm{L}^{16}$ ligand families (Scheme 16, Figures 15 and 18) was tested towards the oxidation of cyclohexane and adamantane with $m$-CPBA: [Ni ${ }^{\mathrm{II}}\left(\mathrm{L}^{13 \mathrm{dc}}\right)_{2} \mathrm{Cl}_{2}$ ] (Ni16), [ $\left[\mathrm{Ni}^{\mathrm{II}}\left(\mathrm{L}^{13 \mathrm{ca}}\right)_{2} \mathrm{Cl}_{2}\right.$ ] $(\mathrm{Ni17}),\left[\mathrm{Ni}^{\mathrm{II}}\left(\mathrm{L}^{13 \mathrm{a}}\right)_{3}\right]\left(\mathrm{BPh}_{4}\right)_{2}(\mathrm{Ni18})$, $\left[\mathrm{Ni}^{\mathrm{II}}\left(\mathrm{L}^{13 \mathrm{cb}}\right)_{3}\right]\left(\mathrm{BPh}_{4}\right)_{2}(\mathrm{Ni19}),\left[\mathrm{Ni}^{\mathrm{II}}\left(\mathrm{L}^{16 \mathrm{a}}\right)\left(\mathrm{CH}_{3} \mathrm{OH}\right) \mathrm{Cl}\right] \mathrm{Cl} \cdot \mathrm{CH}_{3} \mathrm{OH}(\mathbf{N i 2 0}),\left[\mathrm{Ni}^{\mathrm{II}}\left(\mathrm{L}^{16 \mathrm{~b}}\right)_{2} \mathrm{Cl}_{2}\right](\mathbf{N i 2 1})$ $\left[\mathrm{Ni}^{\mathrm{II}}\left(\mathrm{L}^{13 \mathrm{db}}\right)_{2}(\mathrm{OAc})\right]\left(\mathrm{BPh}_{4}\right)(\mathrm{Ni22})$ [23]. The $3^{\circ}: 2^{\circ}$ bond selectivity in the oxidation of adamantane catalyzed by Ni16-Ni22 (and Ni1 under the same conditions) varied from 33:1 to 44:1 for oxygenated products (alcohols and ketones) and from 14:1 to 19:1 for all products (oxygenated and chlorinated ones). Oxidation of cis- and trans-1,2-dimethylcyclohexanes proceeded with almost complete epimerization of the stereoconfiguration. The $\operatorname{ArC}(\mathrm{O}) \mathrm{OO} \bullet$ radical, generated from the photosplitting of a benzyl with the subsequent reaction of the ArCO• acyl radical with $\mathrm{O}_{2}$, revealed a higher $3^{\circ}: 2^{\circ}$ bond selectivity of $35: 1$ in the oxidation of adamantane. The participation of 3-chlorophenyl radical Ar• as the main attacking species was ruled out since the oxidation of deuterated cyclohexane afforded only small amounts of singly deuterated 3-chorobenzene. The EPR spectra of a frozen solution of Ni16 after the addition of five equivalents of $m$-CPBA revealed a broad isotropic line with $\mathrm{g}=2.007$, as expected for an organic radical (while the complex Ni16 is EPR-silent), which is considerably different from the spectra of $\mathrm{Ni}(\mathrm{III})$ species (Figures 6, 11 and 13). The authors concluded that aroyl radical $\mathrm{ArC}(\mathrm{O}) \mathrm{O} \bullet$ is the $\mathrm{C}-\mathrm{H}$ attacking species in all these catalytic systems, where an alkyl radical formed after $\mathrm{H}$ abstraction reacts with $m$-CPBA with the formation of oxygenated products in the course of a chain reaction mechanism, where the role of the catalyst is in the generation of $\operatorname{ArC}(\mathrm{O}) \mathrm{O} \bullet$ radicals only (Scheme 17).<smiles>CC(c1ccccn1)(c1ccccn1)c1cccc(-c2ccccn2)n1</smiles>

$\mathrm{L}^{16 a} \quad \mathrm{~L}^{16 b}$<smiles>Brc1cccc(-c2ccccn2)n1</smiles>

Scheme 16. Schematic representation of the ligand family $\mathrm{L}^{16}$.

An important observation was the complete absence of stereoselectivity when using cis-1,2-dimethylcyclohexane as a substrate (Scheme 3) [23]. This effect can be explained by the formation of a long-lived alkyl radical upon $\mathrm{H}$ abstraction by the $\operatorname{ArC}(\mathrm{O}) \mathrm{O} \bullet$ radical.

The conclusion regarding the radical chain mechanism, however, contradicts some observations reported in the literature. The self-supporting free radical chain usually requires much higher concentrations of the reagents than reported ([alkane $]_{0}=0.06 \mathrm{M}$ and $\left.[m-\mathrm{CPBA}]_{0}=0.03 \mathrm{M}\right)$; otherwise, the side reactions break the chain [61]. In the present case, such side reactions are the decarboxylation of $\operatorname{ArC}(\mathrm{O}) \mathrm{O} \bullet$ radical and the trapping of an alkyl radical with dioxygen (the reactions involving Ni14-Ni18 were carried out in air). The rate of decarboxylation of $\operatorname{ArC}(\mathrm{O}) \mathrm{O} \bullet$ is expected to be comparable to the rate of hydrogen abstraction from a substrate [14], and the rates of the reaction of alkyl 
radicals with molecular oxygen are known to be very high. Large amounts of chlorinated products (up to ca. $50 \%$ based on the oxidant) as well as complete epimerization of alkanes' stereoconfiguration are strong evidence of the presence of free alkyl radicals. However, in the case of some catalytic systems, particularly those proceeding in the absence of a halogen-containing solvent (such as the reaction using Ni8), the significant retention of the stereoconfiguration of dimethylcyclohexane was observed. Oxidation catalyzed by Ni8 did not afford chlorobenzene, which appears from the decarboxylation of the $\operatorname{ArC}(\mathrm{O}) \mathrm{O} \bullet$ radical. Hence, at least for the case of $\mathrm{Ni}$, the $\mathrm{C}-\mathrm{H}$ attacking species are $\mathrm{Ni}{ }^{\mathrm{III}}-\mathrm{O} \bullet$ high-valence metal oxo radicals, but not $\mathrm{ArC}(\mathrm{O}) \mathrm{O} \bullet$ ones. Remarkably, the oxidation of adamantane by $\mathrm{Ni} 8$ resulted in $3^{\circ}: 2^{\circ}$ bond selectivity of $18: 1$, which completely falls within the region presumed for the $\operatorname{ArC}(\mathrm{O}) \mathrm{O} \bullet$ radical, if one considers both oxygenated and halogenated products (Table 1). Therefore, the bond selectivity when used alone could not serve as a reliable marker for the discrimination of the type of $m$-CPBA activation mechanism.

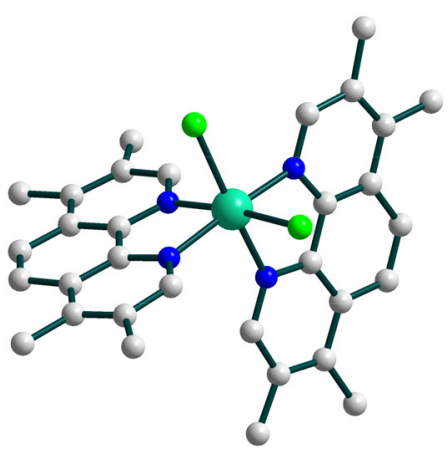

Ni16

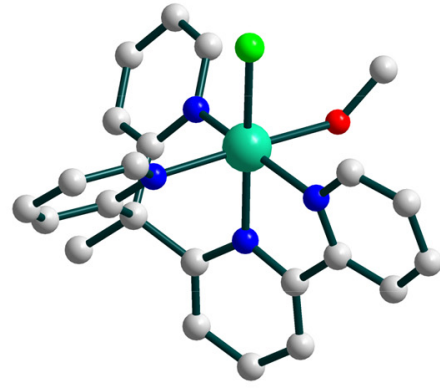

$\mathrm{Ni20}$

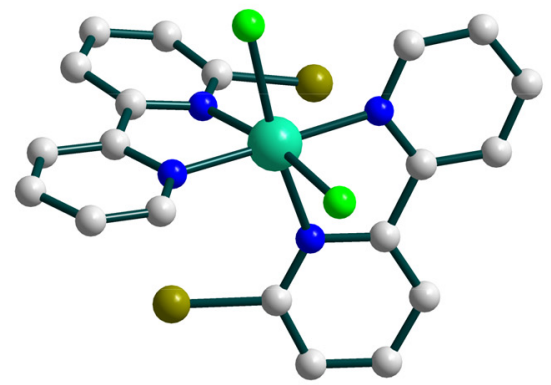

$\mathrm{Ni21}$

Figure 18. Molecular structures of the complexes $\left[\mathrm{Ni}^{\mathrm{II}}\left(\mathrm{L}^{13 \mathrm{dc}}\right)_{2} \mathrm{Cl}_{2}\right](\mathrm{Ni16}),\left[\mathrm{Ni}^{\mathrm{II}}\left(\mathrm{L}^{16 \mathrm{a}}\right)\left(\mathrm{CH}_{3} \mathrm{OH}\right) \mathrm{Cl}\right] \mathrm{Cl} \cdot \mathrm{CH} 3 \mathrm{OH}(\mathrm{Ni20})$ and $\left[\mathrm{Ni}^{\mathrm{II}}\left(\mathrm{L}^{16 \mathrm{~b}}\right)_{2} \mathrm{Cl}_{2}\right.$ ] (Ni21) (CSD refcodes XAGJIC, XAGJUO and XAGJOI, respectively) [23]. The uncoordinated solvent molecules, as well as anions and hydrogen atoms, are omitted for clarity. Color scheme: Ni, light green; $\mathrm{O}$, red; $\mathrm{N}, \mathrm{blue} ; \mathrm{Cl}$, green; Br, brown-green; C, grey.

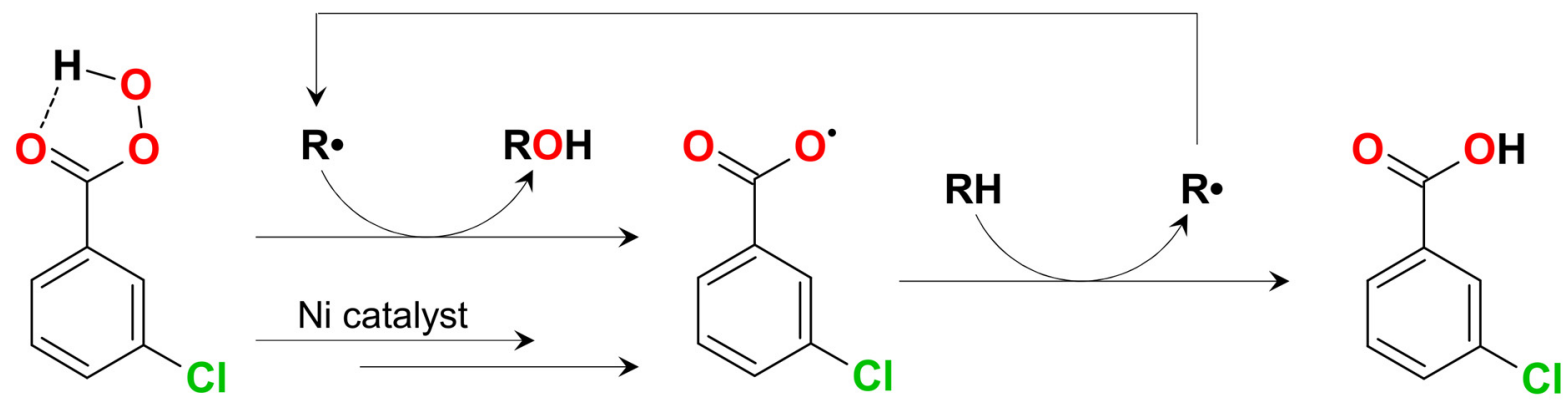

Scheme 17. General reaction pathway of the oxidation of a substrate $(\mathrm{RH})$ with $m$-CPBA catalyzed by nickel complexes, proposed in [23].

In view of the above data, very recently, the catalytic behavior of the complexes Ni1 and Ni2 (Figures 1 and 2) was reinvestigated and compared to that of two complexes, $\left[\mathrm{Ni}^{\mathrm{II}}\left(\mathrm{H}_{2} \mathrm{~L}^{17 \mathrm{a}}\right)(\mathrm{OAc})_{2}\right] \cdot \mathrm{CH}_{3} \mathrm{CN}$ (Ni23) and $\left[\mathrm{Ni}^{\mathrm{II}}\left(\mathrm{H}_{2} \mathrm{~L}^{17 \mathrm{~b}}\right)(\mathrm{TMG})\right] \cdot \mathrm{CH}_{3} \mathrm{CN}$ (Ni24) (where $\mathrm{TMG}=1,1,3,3$-tetramethylguanidine), bearing similar ligands (Scheme 18 and Figure 19) [62]. Both Ni23 and Ni24 catalyzed the oxidation of cyclohexane, with $m$-CPBA producing cyclohexanol and cyclohexanone (as well as trace amounts of $\varepsilon$-caprolactone) with 86 and $25 \%$ yields, respectively [63]. The reaction rates in the oxidation of cyclohexane (under inert atmosphere) exhibited by the catalysts Ni1, Ni2, Ni23 and Ni24 are different: while the catalyst $\mathrm{Ni24}$ demonstrates a $W_{0}$ of $6 \times 10^{-6} \mathrm{M} \mathrm{s}^{-1}$, the complex $\mathrm{Ni} 2$ was found to be most active, with an almost six-times higher rate $W_{0}$ of $32 \times 10^{-6} \mathrm{M} \mathrm{s}^{-1}$ [62]. Noteworthily, 
although the product accumulations curves for all series (Ni1, Ni2, Ni23 and Ni24) are linear in the time span studied (ca. 3-20 min), none of the extrapolated lines pass through the zero point, exhibiting a clear lag period of ca. $2 \mathrm{~min}$. The oxidation of cyclohexane catalyzed by Ni1 was found to be strongly dependent on the atmosphere: while, under $\mathrm{N}_{2}$, the yields of oxygenates and chlorobenzene reached 83 and $34 \%$, respectively, when the same reaction was repeated under $\mathrm{O}_{2}$, the yields dropped to 36 and 1\% [62]. It should be noted that catalyst-free oxidations with $m$-CPBA are also sensitive to air [14] and, therefore, the presence of $\mathrm{O}_{2}$ most likely influences the non-catalytic part (e.g., free radical one) of the mechanism. The possibility of the generation of $\mathrm{Ni}^{\mathrm{II}}-\mathrm{O} \bullet$ species from $\mathrm{Ni1}$ was established from the ESI-MS, Raman and UV/Vis data.

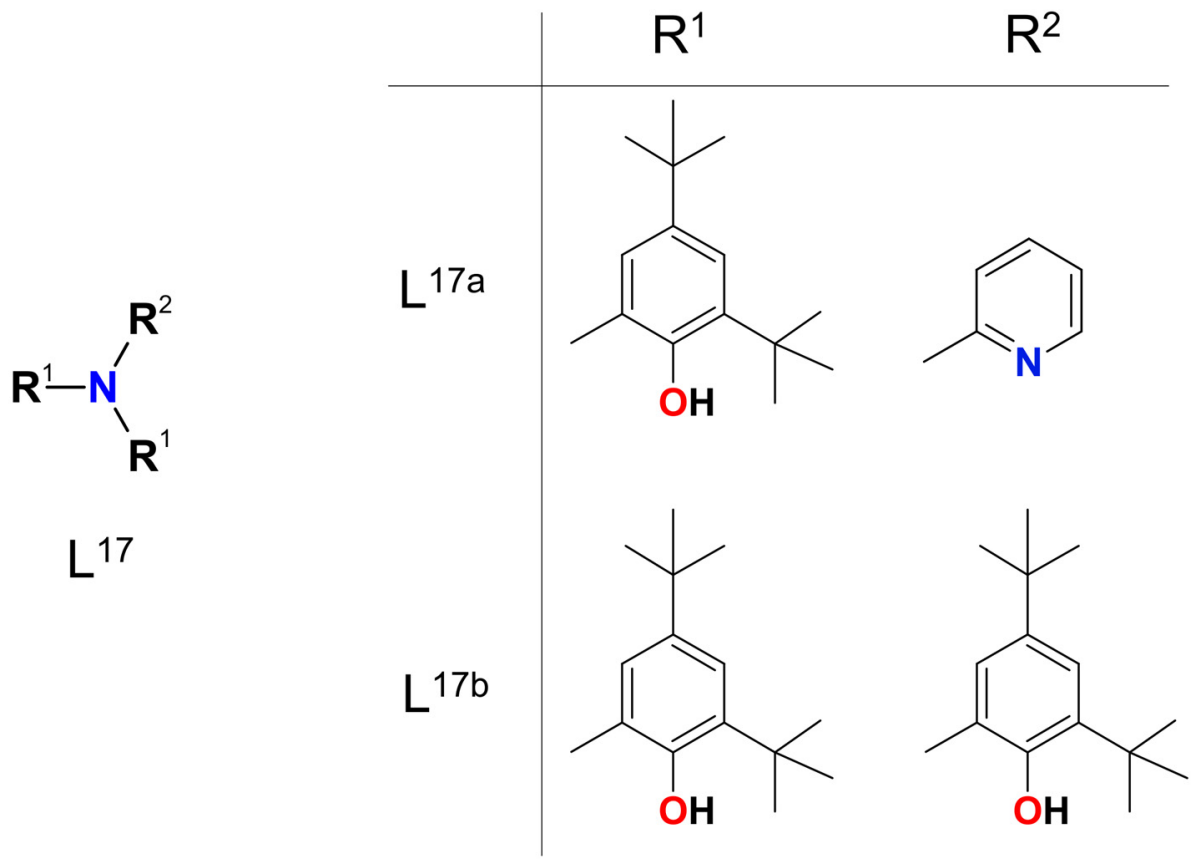

Scheme 18. Schematic representation of the ligand family $L^{17}[62,63]$.

A relatively high value of the kinetic isotope effect (KIE; 6.7) was obtained for the competitive oxidation of normal and deuterated cyclohexanes catalyzed by Ni1 [62]. This value is considerably higher than those observed earlier for Ni1 (2.8 and 3.7) and Ni12 (2.7) $[35,56]$. A plausible explanation for such a difference is in the methods used to calculate the KIE value: while the most recent value (6.7) is based on the reaction rates, all others were obtained by measuring the amounts of normal and deuterated products after 1 $h$. The KIE value may vary drastically depending on the time point at which the amounts of products are recorded; thus, measuring the reaction rates is a more accurate method and, therefore, 6.7 appears to be the true KIE value for Ni1. The authors concluded that while $\operatorname{ArC}(\mathrm{O}) \mathrm{O} \bullet$ is the most plausible $\mathrm{C}-\mathrm{H}$ attacking species, the participation of $\mathrm{Ni}^{\mathrm{II}}-\mathrm{O} \bullet$ ones is also possible. One should note here that the values of $3^{\circ}: 2^{\circ}$ bond selectivity in the oxidation of adamantane (ca. 13 for Ni1; Table 1 ) are close to those expected for ${ }^{t} \mathrm{BuO} \bullet$ and 2-iodobenzoate $\left(\mathrm{Ar}^{2} \mathrm{C}(\mathrm{O}) \mathrm{O} \bullet\right.$ ) radicals (Table 1). Moreover, the KIE of 6.7 is close to the values observed for $\mathrm{Co} / m$-CPBA catalytic systems (6-8), suggesting that all these values are due to similar $\mathrm{C}-\mathrm{H}$ attacking species. 


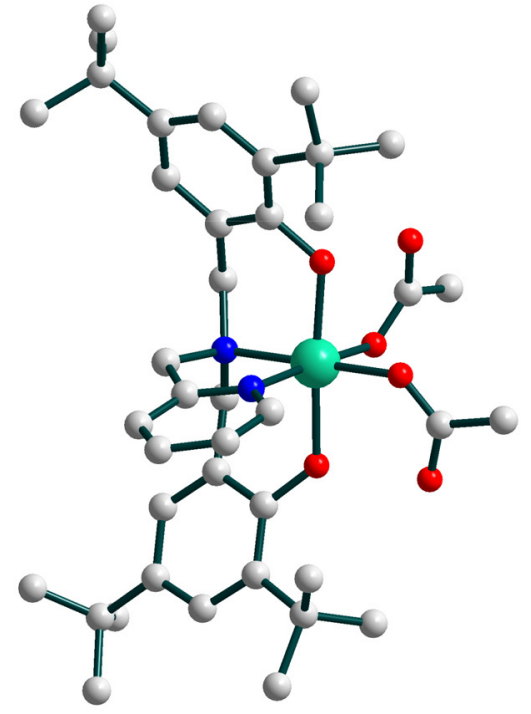

$\mathrm{Ni} 23$

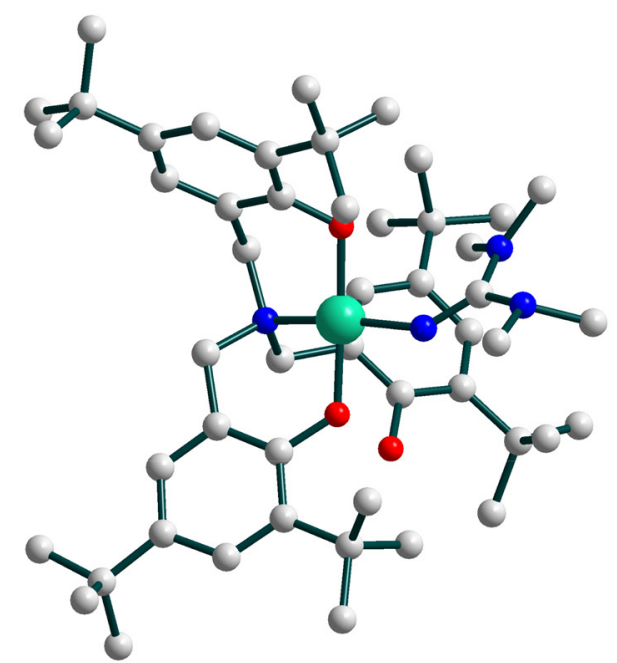

$\mathrm{Ni24}$

Figure 19. Molecular structures of the complexes $\left[\mathrm{Ni}^{\mathrm{II}}\left(\mathrm{H}_{2} \mathrm{~L}^{17 \mathrm{a}}\right)(\mathrm{OAc})_{2}\right] \cdot \mathrm{CH}_{3} \mathrm{CN}$ (Ni23) and $\left[\mathrm{Ni}^{\mathrm{II}}\left(\mathrm{H}_{2} \mathrm{~L}^{17 \mathrm{~b}}\right)(\mathrm{TMG})\right] \cdot \mathrm{CH}_{3} \mathrm{CN}$ (Ni24) (CSD refcodes UDOLIJ and UDOLOP, respectively) [62,63]. The uncoordinated solvent molecules are omitted for clarity. Color scheme: Ni, light green; $\mathrm{N}$, blue; $\mathrm{O}$, red; C, grey.

Table 1. Bond selectivity parameters and mechanistic details of the catalysts discussed.

\begin{tabular}{|c|c|c|c|c|c|c|}
\hline Cat. & Adamantane $^{a}$ & $\mathrm{MeCyH}^{\mathrm{b}}$ & $\begin{array}{c}\text { Proposed C-H } \\
\text { Attacking Species }\end{array}$ & $\begin{array}{l}\text { Proposed O-O } \\
\text { Splitting Type }\end{array}$ & Reaction Media & Ref. \\
\hline Ni1 & 13 & $-c$ & $\mathrm{NiO}^{+}$ & - & $\mathrm{CH}_{2} \mathrm{Cl}_{2} / \mathrm{CH}_{3} \mathrm{CN}^{\mathrm{d}}$ & [35] \\
\hline Ni1 & $36^{\mathrm{e}} / 14^{\mathrm{f}}$ & - & $\mathrm{ArC}(\mathrm{O}) \mathrm{O} \bullet$ & homo & $\mathrm{CH}_{2} \mathrm{Cl}_{2} / \mathrm{CH}_{3} \mathrm{CN}^{\mathrm{d}}$ & [23] \\
\hline Ni1 & 13 & - & $\operatorname{ArC}(\mathrm{O}) \mathrm{O} \bullet / \mathrm{Ni}^{\mathrm{II}}-\mathrm{O} \bullet$ & homo & $\mathrm{CH}_{2} \mathrm{Cl}_{2} / \mathrm{CH}_{3} \mathrm{CN}{ }^{\mathrm{d}}$ & [62] \\
\hline $\mathrm{Ni2}$ & - & - & $\mathrm{Ni}^{\mathrm{II}}-\mathrm{O} \bullet$ & homo & $\mathrm{CH}_{2} \mathrm{Cl}_{2} / \mathrm{CH}_{3} \mathrm{CN}{ }^{\mathrm{d}}$ & [27] \\
\hline $\mathrm{Ni} 3$ & $13-17$ & - & $\mathrm{Ni}{ }^{\mathrm{II}}-\mathrm{O} \bullet$ & homo & $\mathrm{CH}_{2} \mathrm{Cl}_{2} / \mathrm{CH}_{3} \mathrm{CN}{ }^{\mathrm{d}}$ & [37] \\
\hline $\mathrm{Ni} 4$ & $11-12$ & - & $\mathrm{Ni}^{\mathrm{II}}-\mathrm{O} \bullet$ & homo & $\mathrm{CH}_{2} \mathrm{Cl}_{2} / \mathrm{CH}_{3} \mathrm{CN}{ }^{\mathrm{d}}$ & [38] \\
\hline Ni5 & - & - & $\mathrm{Ni}^{\mathrm{III}}-\mathrm{O}^{-}$ & homo & $\mathrm{CH}_{2} \mathrm{Cl}_{2}$ & [39] \\
\hline Ni6 & - & $5: 1$ & $\mathrm{Ni} i^{\mathrm{II}}-\mathrm{O} \bullet / \mathrm{Ni}^{\mathrm{III}}=\mathrm{O}$ & homo/concerted & $\mathrm{CH}_{2} \mathrm{Cl}_{2}$ & [42] \\
\hline Ni7 & - & $8: 2: 1$ & $\begin{array}{l}\text { Ni7 }(m-\mathrm{CPBA}) \\
\text { complex }\end{array}$ & - & $\begin{array}{c}\mathrm{CF}_{3} \mathrm{C}_{6} \mathrm{H}_{5}, \mathrm{CH}_{3} \mathrm{C}_{6} \mathrm{H}_{5} \\
\text { or } \mathrm{C}_{6} \mathrm{H}_{6}\end{array}$ & [48] \\
\hline $\mathrm{Ni} 8$ & 18 & - & $\mathrm{Ni} i_{-O}$ III & hetero & $\mathrm{CH}_{2} \mathrm{Cl}_{2}$ & [49] \\
\hline Ni9 & - & - & $\mathrm{Ni}(\mathrm{III})$ or $\mathrm{Ni}(\mathrm{IV})$ & homo/hetero & $\mathrm{CH}_{2} \mathrm{Cl}_{2} / \mathrm{CH}_{3} \mathrm{CN} \mathrm{g}$ & [50] \\
\hline Ni10 & - & - & $\mathrm{Ni}(\mathrm{III})$ & homo/hetero & $\mathrm{CH}_{2} \mathrm{Cl}_{2} / \mathrm{CH}_{3} \mathrm{CN} \mathrm{g}$ & [51] \\
\hline Ni11 & - & - & - & homo/hetero & $\begin{array}{c}\mathrm{CH}_{3} \mathrm{C}_{6} \mathrm{H}_{5}, \mathrm{CH}_{2} \mathrm{Cl}_{2} \\
\mathrm{CH}_{3} \mathrm{CN}, \text { or } \\
\mathrm{CH}_{3} \mathrm{CN} / \mathrm{H}_{2} \mathrm{O}^{\mathrm{h}}\end{array}$ & [52] \\
\hline Ni12 & 19 & $9: 1$ & - & homo & $\mathrm{CH}_{2} \mathrm{Cl}_{2} / \mathrm{CH}_{3} \mathrm{CN}^{\mathrm{d}}$ & [56] \\
\hline Ni13 & - & - & - & - & $\mathrm{DCE}^{\mathrm{i}}$ or DCE/TCB ${ }^{\mathrm{j}, \mathrm{k}}$ & [58] \\
\hline Ni14 & - & $8: 1$ & $\frac{\mathrm{Ni}^{\mathrm{II}}-}{\mathrm{O} \bullet / \mathrm{ArC}(\mathrm{O}) \mathrm{O} \bullet / \mathrm{Ar} \bullet}$ & homo & $\mathrm{CH}_{2} \mathrm{Cl}_{2} / \mathrm{CH}_{3} \mathrm{CN}{ }^{\mathrm{g}}$ & [59] \\
\hline Ni15 & - & - & - & - & $\mathrm{CH}_{3} \mathrm{CN}$ & [60] \\
\hline Ni16-Ni22 & $30-44^{\mathrm{e}} / 13-21^{\mathrm{f}}$ & - & $\operatorname{ArC}(\mathrm{O}) \mathrm{O} \bullet$ & homo & $\mathrm{CH}_{2} \mathrm{Cl}_{2} / \mathrm{CH}_{3} \mathrm{CN}^{\mathrm{d}}$ & [23] \\
\hline $\mathrm{Ni} 23$ & - & - & $\operatorname{ArC}(\mathrm{O}) \mathrm{O} \bullet / \mathrm{Ni}^{\mathrm{II}}-\mathrm{O} \bullet$ & homo & $\mathrm{CH}_{2} \mathrm{Cl}_{2} / \mathrm{CH}_{3} \mathrm{CN}^{\mathrm{d}}$ & {$[62,63]$} \\
\hline $\mathrm{Ni24}$ & - & - & $\operatorname{ArC}(\mathrm{O}) \mathrm{O} \bullet / \mathrm{Ni}^{\mathrm{II}}-\mathrm{O} \bullet$ & homo & $\mathrm{CH}_{2} \mathrm{Cl}_{2} / \mathrm{CH}_{3} \mathrm{CN}^{\mathrm{d}}$ & {$[62,63]$} \\
\hline $\mathrm{NiCl}_{2}$ & $35^{\mathrm{e}} / 17^{\mathrm{f}}$ & - & - & - & $\mathrm{CH}_{2} \mathrm{Cl}_{2} / \mathrm{CH}_{3} \mathrm{CN}^{\mathrm{d}}$ & [23] \\
\hline $\mathrm{Ni}(\mathrm{OAc})_{2}$ & - & $8: 1$ & - & - & $\mathrm{CH}_{2} \mathrm{Cl}_{2} / \mathrm{CH}_{3} \mathrm{CN}$ & [59] \\
\hline cat. free 1 & $44^{\mathrm{a}}$ & $9: 1$ & - & - & $\mathrm{CH}_{2} \mathrm{Cl}_{2} / \mathrm{CH}_{3} \mathrm{CN}^{\mathrm{d}}$ & {$[23,59]$} \\
\hline other cat. $\mathrm{m}$ & 2 & $6: 3: 1-26: 7: 1^{n}$ & $\mathrm{HO} \bullet$ & - & $\mathrm{CH}_{3} \mathrm{CN}$ & {$[64,65]$} \\
\hline other cat. ${ }^{m}$ & 10 & $60: 10: 1-150: 15: 1^{\mathrm{n}}$ & ${ }^{t} \mathrm{BuO} \bullet$ & - & $\mathrm{CH}_{3} \mathrm{CN}$ & {$[64,66,67]$} \\
\hline
\end{tabular}


Table 1. Cont.

\begin{tabular}{|c|c|c|c|c|c|c|}
\hline Cat. & Adamantane ${ }^{a}$ & $\mathrm{MeCyH}^{\mathrm{b}}$ & $\begin{array}{c}\text { Proposed C-H } \\
\text { Attacking Species }\end{array}$ & $\begin{array}{l}\text { Proposed O-O } \\
\text { Splitting Type }\end{array}$ & Reaction Media & Ref. \\
\hline cat. free. $^{o}$ & $>6$ & - & $\mathrm{Ar}^{2} \mathrm{C}(\mathrm{O}) \mathrm{O} \bullet \mathrm{p}$ & - & $\mathrm{ClC}_{6} \mathrm{H}_{5}$ & [68] \\
\hline cat. free $\mathrm{q}$ & $33^{e}$ & - & $\mathrm{PhC}(\mathrm{O}) \mathrm{OO} \bullet$ & - & DCE & [23] \\
\hline
\end{tabular}

${ }^{a}$ Normalized $3^{\circ}: 2^{\circ}$ bond selectivity in adamantane oxidation. The numbers in the column show the prevalence of a tertiary product $\left(3 \times 3^{\circ}\right.$ products $/ 2^{\circ}$ products); ${ }^{\mathrm{b}}$ normalized $3^{\circ}: 2^{\circ}$ bond selectivity in methylcyclohexane oxidation $\left(3^{\circ}\right.$ product: $\left(2^{\circ}\right.$ products $\left./ 10\right):\left(1^{\circ}\right.$ products $\left.\left./ 3\right)\right)$. In the cases where the $1^{\circ}$ products were not detected (or their amounts were negligible), only the $3^{\circ}: 2^{\circ}$ ratio is shown; ${ }^{\mathrm{c}}$ no data; ${ }^{\mathrm{d}} 3: 1$ ratio; ${ }^{\mathrm{e}}$ hydroxylation products only; ${ }^{\mathrm{f}}$ hydroxylation and halogenation products; ${ }^{\mathrm{g}} 1: 1$ ratio; ${ }^{\mathrm{h}}$ 95:5 or $6: 9$ ratios; ${ }^{\mathrm{i}} 1$,2-dichloromethane; ${ }^{\mathrm{j}} 1,2,4$-trichlorobenzene; ${ }^{k} 3: 1$ or $1: 1$ ratios; $^{1}$ oxidation with $m$-CPBA in the absence of a catalyst; ${ }^{m}$ the other types of catalysts, generating the respective $\mathrm{RO} \bullet$ radicals; ${ }^{\mathrm{n}}$ the range of typical ratios; ${ }^{\circ}$ radical chain reaction initiated by catalytic amounts of benzoyl peroxide at $100{ }^{\circ} \mathrm{C} ; \mathrm{P} \mathrm{Ar}^{2}=2$-iodobenzoate; $\mathrm{q}^{\mathrm{a}}$ the radical $\mathrm{PhC}(\mathrm{O}) \mathrm{OO} \bullet$ was generated by the homolytic photosplitting of benzil under $\mathrm{O}_{2}$ atmosphere.

\section{Concluding Remarks}

The field of the metal-catalyzed oxidation of organic compounds with $m$-CPBA has attracted great attention due to the possibility of the selective functionalization of organic substrates under mild conditions. Complexes of nickel exhibit notable catalytic activity and, at the same time, form high-valence intermediates with a lifetime that is sufficient for their trapping using conventional spectroscopic methods. The establishment of ligand systems allowing the isolation of a stable $\mathrm{Ni} / \mathrm{m}$-CPBA adduct is remarkable. However, despite the significant improvements in the field, the details of the $m$-CPBA cleavage mechanism and factors that suppress the undesired free radical activity are still to be established. One of the principal problems is the lack of systematic mechanistic tests that would help in the discrimination between metal-based attacking species and organic radicals formed from $m$-CPBA. We summarize below a few observations that we believe could help to establish the type of $m$-CPBA action mechanism in a certain case.

Although many nickel catalysts demonstrate similar activity and selectivity (Table 1), those bearing planar ligands (e.g., pincer-like Ni8, or porphyrin Ni11) differ by elevated selectivity, supported by lower yields of chlorobenzene, indicating a greater contribution of $m$-CPBA O-O bond heterolysis. This could be associated with the diamagnetic singlet spin state of $\mathrm{Ni}$ (II) ions in these complexes or the impossibility of bidentate coordination of $m$-CPBA to a nickel center due to the sterical hindrance of the ligands.

Blank tests in the absence of catalysts are mandatory because $m$-CPBA is known to epoxidize olefines and even oxidize weak $\mathrm{C}-\mathrm{H}$ bonds $[14,69]$. Hence, in the event that the catalyst shows low activity, the effect of a catalyst-free background reaction should be always considered. Another suggestion concerns the ${ }^{18} \mathrm{O}$-labeling tests: one should always keep in mind the possibility of direct oxygen exchange between $\mathrm{H}_{2}{ }^{18} \mathrm{O}$ and the product(s) and/or oxidant. Ketones are known to rapidly exchange oxygen with water [44-47]; thus, the observation of their large ${ }^{18} \mathrm{O}$-enrichment may be misleading. Although alcohols are less prone to such activity, some tertiary alcohols (such as cumyl alcohol or 2,3-dimethyl2-butanol) could accumulate notable amounts of ${ }^{18} \mathrm{O}$ directly from $\mathrm{H}_{2}{ }^{18} \mathrm{O}$. Further, in contrast to $\mathrm{H}_{2} \mathrm{O}_{2}$, peroxyacids show very complex behavior and, therefore, the possibility of their catalyst-free ${ }^{18} \mathrm{O}$-enrichment should not be excluded. Neglecting these factors when performing mechanistic tests using $\mathrm{H}_{2}{ }^{18} \mathrm{O}$ may lead to incorrect conclusions.

The formation of chlorobenzene is direct evidence of the $m$-CPBA O-O bond homolysis and the presence of highly reactive free radicals, primarily $\operatorname{ArC}(\mathrm{O}) \mathrm{O} \bullet$ and Ar• [14]. Therefore, whenever significant amounts of chlorobenzene are observed, the proposal for HVMO intermediates as the principal attacking species should be made only after careful evaluation of the reaction between the substrate and organic radicals. Oxidation of dimethylcyclohexane is a simple and efficient test (Scheme 3) [31,32] that could be performed in this case, where epimerization of the initial stereoconfiguration is expected for hydrogen abstraction by R• species. However, one should keep in mind that even a radical rebound mechanism may lead to some degree of epimerization due to the "radical escape" [70], and some organic radicals, such as $\operatorname{ArC}(\mathrm{O}) \mathrm{OO} \bullet$, may oxidize substrates with rather high selectivity $[14,71]$. Finally, one should avoid using high concentrations of a 
substrate and $m$-CPBA during mechanistic investigations to prevent the initiation of a radical chain reaction, which eventually may lead to the formation of $\operatorname{ArC}(\mathrm{O}) \mathrm{OO} \bullet$.

Despite the recognized promoting effect of acidic additives in catalytic oxidations with $\mathrm{H}_{2} \mathrm{O}_{2}[6,72]$, most of the catalytic investigations where $m$-CPBA is an oxidant still do not use this option. There is evidence that the presence of small amounts of an acidic promoter suppress the free radical reaction in the case of a cobalt catalyst and $m$-CPBA oxidant $[33,34,73]$. One may expect a similar effect to be exhibited for other kinds of catalysts.

As a final remark, the rapidly growing field of the catalytic oxidation of valuable organic substrates requires the use of abundant first-row metals (such as nickel) as catalysts [74], where polynuclear and heterometallic compounds may be of special interest $[6,75]$. Many mechanisms of oxidative functionalization with peroxides are still to be explored and further efforts are needed to fulfil the demands of the fine catalysis and chemical industry.

Author Contributions: D.S.N. and O.V.N. contributed equally. All authors have read and agreed to the published version of the manuscript.

Funding: This work was supported by the Foundation for Science and Technology (FCT), Portugal (projects UIDB/00100/2020 of Centro de Química Estrutural, PTDC/QUI-QIN/29778/2017, contracts IST-ID/086/2018 (D.S.N.) and IST-ID/117/2018 (O.V.N.)).

Conflicts of Interest: The authors declare no conflict of interest.

\section{References}

1. Hou, H.L.; Zeng, X.K.; Zhang, X.W. Production of Hydrogen Peroxide by Photocatalytic Processes. Angew. Chem. Int. Edit. 2020, 59, 17356-17376. [CrossRef]

2. Yi, H.; Zhang, G.T.; Wang, H.M.; Huang, Z.Y.; Wang, J.; Singh, A.K.; Lei, A.W. Recent Advances in Radical C-H Activation/Radical Cross-Coupling. Chem. Rev. 2017, 117, 9016-9085. [CrossRef] [PubMed]

3. Nosaka, Y.; Nosaka, A.Y. Generation and Detection of Reactive Oxygen Species in Photocatalysis. Chem. Rev. 2017, 117, 11302-11336. [CrossRef] [PubMed]

4. Gandhi, H.; O’Reilly, K.; Gupta, M.K.; Horgan, C.; O'Leary, E.M.; O'Sullivan, T.P. Advances in the synthesis of acyclic peroxides. RSC Adv. 2017, 7, 19506-19556. [CrossRef]

5. Shilov, A.E.; Shul'pin, G.B. Activation of C-H bonds by metal complexes. Chem. Rev. 1997, 97, 2879-2932. [CrossRef] [PubMed]

6. Nesterov, D.S.; Nesterova, O.V.; Pombeiro, A.J.L. Homo- and heterometallic polynuclear transition metal catalysts for alkane C-H bonds oxidative functionalization: Recent advances. Coord. Chem. Rev. 2018, 355, 199-222. [CrossRef]

7. Wang, V.C.C.; Maji, S.; Chen, P.R.Y.; Lee, H.K.; Yu, S.S.F.; Chan, S.I. Alkane Oxidation: Methane Monooxygenases, Related Enzymes, and Their Biomimetics. Chem. Rev. 2017, 117, 8574-8621. [CrossRef] [PubMed]

8. O'Reilly, E.; Kohler, V.; Flitsch, S.L.; Turner, N.J. Cytochromes P450 as useful biocatalysts: Addressing the limitations. Chem. Commun. 2011, 47, 2490-2501. [CrossRef]

9. Targhan, H.; Evans, P.; Bahrami, K. A Review of the Role of Hydrogen Peroxide in Organic Transformations. J. Ind. Eng. Chem. 2021. [CrossRef]

10. Ghosh, P.; Ganguly, B.; Das, S. NaI/KI/NH$/ \mathrm{NH}_{4}$ and TBHP as powerful oxidation systems: Use in the formation of various chemical bonds. Org. Biomol. Chem. 2021, 19, 2146-2167. [CrossRef]

11. Wu, X.F.; Gong, J.L.; Qi, X.X. A powerful combination: Recent achievements on using TBAI and TBHP as oxidation system. Org. Biomol. Chem. 2014, 12, 5807-5817. [CrossRef] [PubMed]

12. Yoshimura, A.; Zhdankin, V.V. Advances in Synthetic Applications of Hypervalent Iodine Compounds. Chem. Rev. 2016, 116, 3328-3435. [CrossRef] [PubMed]

13. Fokin, A.A.; Schreiner, P.R. Selective alkane transformations via radicals and radical cations: Insights into the activation step from experiment and theory. Chem. Rev. 2002, 102, 1551-1593. [CrossRef] [PubMed]

14. Bravo, A.; Bjorsvik, H.R.; Fontana, F.; Minisci, F.; Serri, A. Radical versus "oxenoid" oxygen insertion mechanism in the oxidation of alkanes and alcohols by aromatic peracids. New synthetic developments. J. Org. Chem. 1996, 61, 9409-9416. [CrossRef]

15. Hussain, H.; Al-Harrasi, A.; Green, I.R.; Ahmed, I.; Abbas, G.; Rehman, N.U. meta-Chloroperbenzoic acid (mCPBA): A versatile reagent in organic synthesis. RSC Adv. 2014, 4, 12882-12917. [CrossRef]

16. Chen, M.M.; Coelho, P.S.; Arnold, F.H. Utilizing Terminal Oxidants to Achieve P450-Catalyzed Oxidation of Methane. Adv. Synth. Catal. 2012, 354, 964-968. [CrossRef]

17. Kudrik, E.V.; Afanasiev, P.; Alvarez, L.X.; Dubourdeaux, P.; Clemancey, M.; Latour, J.M.; Blondin, G.; Bouchu, D.; Albrieux, F.; Nefedov, S.E.; et al. An N-bridged high-valent diiron-oxo species on a porphyrin platform that can oxidize methane. Nat. Chem. 2012, 4, 1024-1029. [CrossRef] 
18. Lyakin, O.Y.; Bryliakov, K.P.; Talsi, E.P. Non-heme oxoiron(V) intermediates in chemo-, regio- and stereoselective oxidation of organic substrates. Coord. Chem. Rev. 2019, 384, 126-139. [CrossRef]

19. Singh, F.V.; Wirth, T. Hypervalent Iodine-Catalyzed Oxidative Functionalizations Including Stereoselective Reactions. Chem. Asian J. 2014, 9, 950-971. [CrossRef]

20. Clavier, H.; Pellissier, H. Recent Developments in Enantioselective Metal-Catalyzed Domino Reactions. Adv. Synth. Catal. 2012, 354, 3347-3403. [CrossRef]

21. Ray, K.; Pfaff, F.F.; Wang, B.; Nam, W. Status of Reactive Non-Heme Metal-Oxygen Intermediates in Chemical and Enzymatic Reactions. J. Am. Chem. Soc. 2014, 136, 13942-13958. [CrossRef] [PubMed]

22. Sankaralingam, M.; Balamurugan, M.; Palaniandavar, M. Alkane and alkene oxidation reactions catalyzed by nickel(II) complexes: Effect of ligand factors. Coord. Chem. Rev. 2020, 403, 14. [CrossRef]

23. Qiu, Y.H.; Hartwig, J.F. Mechanism of Ni-Catalyzed Oxidations of Unactivated C(sp $\left.{ }^{3}\right)$-H Bonds. J. Am. Chem. Soc. 2020, 142, 19239-19248. [CrossRef]

24. Pirovano, P.; Twamley, B.; McDonald, A.R. Modulation of Nickel Pyridinedicarboxamidate Complexes to Explore the Properties of High-valent Oxidants. Chem. Eur. J. 2018, 24, 5238-5245. [CrossRef]

25. Corona, T.; Draksharapu, A.; Padamati, S.K.; Gamba, I.; Martin-Diaconesou, V.; Acuna-Pares, F.; Browne, W.R.; Company, A. Rapid Hydrogen and Oxygen Atom Transfer by a High-Valent Nickel-Oxygen Species. J. Am. Chem. Soc. 2016, 138, 12987-12996. [CrossRef] [PubMed]

26. Pirovano, P.; Farquhar, E.R.; Swart, M.; McDonald, A.R. Tuning the Reactivity of Terminal Nickel(III)-Oxygen Adducts for C-H Bond Activation. J. Am. Chem. Soc. 2016, 138, 14362-14370. [CrossRef]

27. Nagataki, T.; Ishii, K.; Tachi, Y.; Itoh, S. Ligand effects on $\mathrm{Ni}^{\mathrm{II}}$-catalysed alkane-hydroxylation with m-CPBA. Dalton Trans. 2007, 1120-1128. [CrossRef]

28. Shul'pin, G.B. New Trends in Oxidative Functionalization of Carbon-Hydrogen Bonds: A Review. Catalysts 2016, 6, 50. [CrossRef]

29. Olivo, G.; Cusso, O.; Borrell, M.; Costas, M. Oxidation of alkane and alkene moieties with biologically inspired nonheme iron catalysts and hydrogen peroxide: From free radicals to stereoselective transformations. J. Biol. Inorg. Chem. 2017, 22, 425-452. [CrossRef]

30. Nesterova, O.V.; Kopylovich, M.N.; Nesterov, D.S. Stereoselective oxidation of alkanes with m-CPBA as an oxidant and cobalt complex with isoindole-based ligands as catalysts. RSC Adv. 2016, 6, 93756-93767. [CrossRef]

31. Olivo, G.; Lanzalunga, O.; Di Stefano, S. Non-Heme Imine-Based Iron Complexes as Catalysts for Oxidative Processes. Adv. Synth. Catal. 2016, 358, 843-863. [CrossRef]

32. Serrano-Plana, J.; Oloo, W.N.; Acosta-Rueda, L.; Meier, K.K.; Verdejo, B.; Garcia-Espana, E.; Basallote, M.G.; Munck, E.; Que, L.; Company, A.; et al. Trapping a Highly Reactive Nonheme Iron Intermediate That Oxygenates Strong C-H Bonds with Stereoretention. J. Am. Chem. Soc. 2015, 137, 15833-15842. [CrossRef] [PubMed]

33. Nesterova, O.V.; Kasyanova, K.V.; Makhankova, V.G.; Kokozay, V.N.; Vassilyeva, O.Y.; Skelton, B.W.; Nesterov, D.S.; Pombeiro, A.J.L. Stereospecific sp ${ }^{3}$ C-H oxidation with $m$-CPBA: A Co ${ }^{\text {III }}$ Schiff base complex as pre-catalyst $v$ s. its Co ${ }^{\text {III }} \mathrm{Cd}^{\mathrm{II}}$ heterometallic derivative. Appl. Catal. A 2018, 560, 171-184. [CrossRef]

34. Nesterova, O.V.; Kasyanova, K.V.; Buvaylo, E.A.; Vassilyeva, O.Y.; Skelton, B.W.; Nesterov, D.S.; Pombeiro, A.J.L. Heterometallic $\mathrm{Co}^{\mathrm{III}} \mathrm{Zn}^{\mathrm{II}}$ Schiff Base Catalyst for Mild Hydroxylation of C( $\left.\mathrm{sp}^{3}\right)-\mathrm{H}$ Bonds of Unactivated Alkanes: Evidence for Dual Mechanism Controlled by the Promoter. Catalysts 2019, 9, 209. [CrossRef]

35. Nagataki, T.; Tachi, Y.; Itoh, S. NiII (TPA) as an efficient catalyst for alkane hydroxylation with m-CPBA. Chem. Commun. 2006, 4016-4018. [CrossRef] [PubMed]

36. Talsi, E.P.; Bryliakov, K.P. Chemo- and stereoselective C-H oxidations and epoxidations/cis-dihydroxylations with $\mathrm{H}_{2} \mathrm{O}_{2}$, catalyzed by non-heme iron and manganese complexes. Coord. Chem. Rev. 2012, 256, 1418-1434. [CrossRef]

37. Balamurugan, M.; Mayilmurugan, R.; Suresh, E.; Palaniandavar, M. Nickel(II) complexes of tripodal $4 \mathrm{~N}$ ligands as catalysts for alkane oxidation using m-CPBA as oxidant: Ligand stereoelectronic effects on catalysis. Dalton Trans. 2011, 40, 9413-9424. [CrossRef] [PubMed]

38. Sankaralingam, M.; Balamurugan, M.; Palaniandavar, M.; Vadivelu, P.; Suresh, C.H. Nickel(II) Complexes of Pentadentate N5 Ligands as Catalysts for Alkane Hydroxylation by Using m-CPBA as Oxidant: A Combined Experimental and Computational Study. Chem. Eur. J. 2014, 20, 11346-11361. [CrossRef]

39. Pfaff, F.F.; Heims, F.; Kundu, S.; Mebs, S.; Ray, K. Spectroscopic capture and reactivity of $S=1 / 2$ nickel(III)-oxygen intermediates in the reaction of a Ni ${ }^{\mathrm{II}}$-salt with mCPBA. Chem. Commun. 2012, 48, 3730-3732. [CrossRef]

40. Krzystek, J.; Ozarowski, A.; Telser, J. Multi-frequency, high-field EPR as a powerful tool to accurately determine zero-field splitting in high-spin transition metal coordination complexes. Coord. Chem. Rev. 2006, 250, 2308-2324. [CrossRef]

41. Krzystek, J.; Park, J.H.; Meisel, M.W.; Hitchman, M.A.; Stratemeier, H.; Brunel, L.C.; Telser, J. EPR spectra from "EPR-silent" species: High-frequency and high-field EPR spectroscopy of pseudotetrahedral complexes of nickel(II). Inorg. Chem. 2002, 41, 4478-4487. [CrossRef]

42. Hikichi, S.; Hanaue, K.; Fujimura, T.; Okuda, H.; Nakazawa, J.; Ohzu, Y.; Kobayashi, C.; Akita, M. Characterization of nickel(II)acylperoxo species relevant to catalytic alkane hydroxylation by nickel complex with mCPBA. Dalton Trans. 2013, 42, 3346-3356. [CrossRef] [PubMed] 
43. Hikichi, S.; Kobayashi, C.; Yoshizawa, M.; Akita, M. Tuning the Stability and Reactivity of Metal-bound Alkylperoxide by Remote Site Substitution of the Ligand. Chem. Asian J. 2010, 5, 2086-2092. [CrossRef]

44. Astakhov, G.S.; Bilyachenko, A.N.; Korlyukov, A.A.; Levitsky, M.M.; Shul'pina, L.S.; Bantreil, X.; Lamaty, F.; Vologzhanina, A.V.; Shubina, E.S.; Dorovatovskii, P.V.; et al. High-Cluster $\left(\mathrm{Cu}_{9}\right)$ Cage Silsesquioxanes: Synthesis, Structure, and Catalytic Activity. Inorg. Chem. 2018, 57, 11524-11529. [CrossRef]

45. Bilyachenko, A.N.; Levitsky, M.M.; Yalymov, A.I.; Korlyukov, A.A.; Vologzhanina, A.V.; Kozlov, Y.N.; Shul'pina, L.S.; Nesterov, D.S.; Pombeiro, A.J.L.; Lamaty, F.; et al. A heterometallic $\left(\mathrm{Fe}_{6} \mathrm{Na}_{8}\right)$ cage-like silsesquioxane: Synthesis, structure, spin glass behavior and high catalytic activity. RSC Adv. 2016, 6, 48165-48180. [CrossRef]

46. Ottenbacher, R.V.; Samsonenko, D.G.; Talsi, E.P.; Bryliakov, K.P. Highly Enantioselective Bioinspired Epoxidation of ElectronDeficient Olefins with $\mathrm{H}_{2} \mathrm{O}_{2}$ on Aminopyridine Mn Catalysts. ACS Catal. 2014, 4, 1599-1606. [CrossRef]

47. Talsi, E.P.; Ottenbacher, R.V.; Bryliakov, K.P. Bioinspired oxidations of aliphatic C-H groups with $\mathrm{H}_{2} \mathrm{O}_{2}$ in the presence of manganese complexes. J. Organomet. Chem. 2015, 793, 102-107. [CrossRef]

48. Nakazawa, J.; Terada, S.; Yamada, M.; Hikichi, S. Structural Characterization and Oxidation Reactivity of a Nickel(II) Acylperoxo Complex. J. Am. Chem. Soc. 2013, 135, 6010-6013. [CrossRef] [PubMed]

49. Corona, T.; Pfaff, F.F.; Acuna-Pares, F.; Draksharapu, A.; Whiteoak, C.J.; Martin-Diaconescu, V.; Lloret-Fillol, J.; Browne, W.R.; Ray, K.; Company, A. Reactivity of a Nickel(II) Bis(amidate) Complex with meta-Chloroperbenzoic Acid: Formation of a Potent Oxidizing Species. Chem. Eur. J. 2015, 21, 15029-15038. [CrossRef]

50. Bok, K.H.; Lee, M.M.; You, G.R.; Ahn, H.M.; Ryu, K.Y.; Kim, S.-J.; Kim, Y.; Kim, C. Synthesis, Characterization, and Catalytic Activities of a Nickel(II) Monoamido-Tetradentate Complex: Evidence for $\mathrm{Ni}^{\mathrm{III}}$-Oxo and $\mathrm{Ni}^{\mathrm{IV}}$-Oxo Species. Chem. Eur. J. 2017, 23, 3117-3125. [CrossRef] [PubMed]

51. Jeong, A.R.; Shin, J.W.; Jeong, J.H.; Bok, K.H.; Kim, C.; Jeong, D.; Cho, J.; Hayami, S.; Min, K.S. Dinuclear Iron(III) and Nickel(II) Complexes Containing N-(2-Pyridylmethyl)-N'-(2-hydroxyethyl)ethylenediamine: Catalytic Oxidation and Magnetic Properties. Chem. Eur. J. 2017, 23, 3023-3033. [CrossRef]

52. Kim, C.; Ahn, H.; Bae, J.; Kim, M.; Bok, K.; Jeong, H.; Lee, S. Synthesis, characterization, and efficient catalytic activities of a nickel(II) porphyrin: Remarkable solvent and substrate effects on participation of multiple active oxidants. Chem. Eur. J. 2017, 23, 11969-11976. [CrossRef]

53. Nesterov, D.S.; Nesterova, O.V.; Kopylovich, M.N.; Pombeiro, A.J.L. Pronounced retention of stereoconfiguration upon $\mathrm{sp}^{3}$ C-H bonds hydroxylation of dimethylcyclohexanes and decahydronaphthalenes with $m$-CPBA oxidant and a Co-phthalocyanine catalyst. Mol. Catal. 2018, 459, 8-15. [CrossRef]

54. Guo, M.; Lee, Y.M.; Fukuzumi, S.; Nam, W. Biomimetic metal-oxidant adducts as active oxidants in oxidation reactions. Coord. Chem. Rev. 2021, 435, 23. [CrossRef]

55. Larson, V.A.; Battistella, B.; Ray, K.; Lehnert, N.; Nam, W. Iron and manganese oxo complexes, oxo wall and beyond. Nat. Rev. Chem. 2020, 4, 404-419. [CrossRef]

56. Terao, I.; Horii, S.; Nakazawa, J.; Okamura, M.; Hikichi, S. Efficient alkane hydroxylation catalysis of nickel(II) complexes with oxazoline donor containing tripodal tetradentate ligands. Dalton Trans. 2020, 49, 6108-6118. [CrossRef]

57. Nesterova, O.V.; Nesterov, D.S.; Jezierska, J.; Pombeiro, A.J.L.; Ozarowski, A. Copper(II) Complexes with Bulky N-Substituted Diethanolamines: High-Field Electron Paramagnetic Resonance, Magnetic, and Catalytic Studies in Oxidative Cyclohexane Amidation. Inorg. Chem. 2018, 57, 12384-12397. [CrossRef] [PubMed]

58. Bunescu, A.; Lee, S.W.; Li, Q.; Hartwig, J.F. Catalytic Hydroxylation of Polyethylenes. Acs. Cent. Sci. 2017, 3, 895-903. [CrossRef] [PubMed]

59. Izumi, T.; Matsuba, N.; Nakazawa, J.; Hikichi, S. Aliphatic C-H hydroxylation activity and durability of a nickel complex catalyst according to the molecular structure of the bis(oxazoline) ligands. Mol. Catal. 2021, 511, 111718. [CrossRef]

60. Bilyachenko, A.N.; Yalymov, A.I.; Shul'pina, L.S.; Mandelli, D.; Korlyukov, A.A.; Vologzhanina, A.V.; Es'kova, M.A.; Shubina, E.S.; Levitsky, M.M.; Shul'pin, G.B. Novel Cage-Like Hexanuclear Nickel(II) Silsesquioxane. Synthesis, Structure, and Catalytic Activity in Oxidations with Peroxides. Molecules 2016, 21, 665. [CrossRef] [PubMed]

61. Shul'pin, G.B.; Kozlov, Y.N.; Nizova, G.V.; Suss-Frank, G.; Stanislas, S.; Kitaygorodskiy, A.; Kulikova, V.S. Oxidations by the reagent $\mathrm{O}_{2}-\mathrm{H}_{2} \mathrm{O}_{2}$-vanadium derivative-pyrazine-2-carboxylic acid. Part 12. Main features, kinetics and mechanism of alkane hydroperoxidation. J. Chem. Soc. Perkin Trans. 2 2001, 1351-1371. [CrossRef]

62. Shinke, T.; Itoh, M.; Wada, T.; Morimoto, Y.; Yanagisawa, S.; Sugimoto, H.; Kubo, M.; Itoh, S. Revisiting Alkane Hydroxylation with m-CPBA (m-Chloroperbenzoic Acid Catalyzed by Nickel(II) Complexes. Chem. Eur. J. 2021. [CrossRef]

63. Nagataki, T.; Itoh, S. Catalytic alkane hydroxylation reaction with nickel(II) complexes supported by di- and triphenol ligands. Chem. Lett. 2007, 36, 748-749. [CrossRef]

64. Vinogradov, M.M.; Kozlov, Y.N.; Bilyachenko, A.N.; Nesterov, D.S.; Shul'pina, L.S.; Zubavichus, Y.V.; Pombeiro, A.J.L.; Levitsky, M.M.; Yalymov, A.I.; Shul'pin, G.B. Alkane oxidation with peroxides catalyzed by cage-like copper(II) silsesquioxanes. New J. Chem. 2015, 39, 187-199. [CrossRef]

65. Buvaylo, E.A.; Kokozay, V.N.; Vassilyeva, O.Y.; Skelton, B.W.; Nesterova, O.V.; Pombeiro, A.J.L. Copper(II) complex of the 2-pyridinecarbaldehyde aminoguanidine Schiff base: Crystal structure and catalytic behaviour in mild oxidation of alkanes. Inorg. Chem. Commun. 2017, 78, 85-90. [CrossRef] 
66. Biswas, A.N.; Pariyar, A.; Bose, S.; Das, P.; Bandyopadhyay, P. Mild oxidation of hydrocarbons catalyzed by iron corrole with tert-butylhydroperoxide. Catal. Commun. 2010, 11, 1008-1011. [CrossRef]

67. Costas, M.; Chen, K.; Que, L. Biomimetic nonheme iron catalysts for alkane hydroxylation. Coord. Chem. Rev. 2000, 200, 517-544. [CrossRef]

68. Zhdankin, V.V.; Krasutsky, A.P.; Kuehl, C.J.; Simonsen, A.J.; Woodward, J.K.; Mismash, B.; Bolz, J.T. Preparation, X-ray crystal structure, and chemistry of stable azidoiodinanes-derivatives of benziodoxole. J. Am. Chem. Soc. 1996, 118, 5192-5197. [CrossRef]

69. Schneider, H.J.; Muller, W. Selective Functionalization of Hydrocarbons. 6. Mechanistic and Preparative Studies on the Regioselective and Stereoselective Paraffin Hydroxylation with Peracids. J. Org. Chem. 1985, 50, 4609-4615. [CrossRef]

70. Cho, K.B.; Wu, X.; Lee, Y.M.; Kwon, Y.H.; Shaik, S.; Nam, W. Evidence for an Alternative to the Oxygen Rebound Mechanism in C-H Bond Activation by Non-Heme Fe ${ }^{\mathrm{IV}}$ O Complexes. J. Am. Chem. Soc. 2012, 134, 20222-20225. [CrossRef] [PubMed]

71. Bravo, A.; Fontana, F.; Minisci, F.; Serri, A. 'Oxenoid' oxygen insertion vs. a radical mechanism in the oxidation of alkanes and alcohols: The case of aromatic peracids. J. Chem. Soc. Chem. Commun. 1996, 1843-1844. [CrossRef]

72. Oloo, W.N.; Que, L. Bioinspired Nonheme Iron Catalysts for C-H and C=C Bond Oxidation: Insights into the Nature of the Metal-Based Oxidants. Acc. Chem. Res. 2015, 48, 2612-2621. [CrossRef] [PubMed]

73. Shul'pin, G.B.; Loginov, D.A.; Shul'pina, L.S.; Ikonnikov, N.S.; Idrisov, V.O.; Vinogradov, M.M.; Osipov, S.N.; Nelyubina, Y.V.; Tyubaeva, P.M. Stereoselective Alkane Oxidation with meta-Chloroperoxybenzoic Acid (MCPBA) Catalyzed by Organometallic Cobalt Complexes. Molecules 2016, 21, 1593. [CrossRef] [PubMed]

74. Gandeepan, P.; Muller, T.; Zell, D.; Cera, G.; Warratz, S.; Ackermann, L. 3d Transition Metals for C-H Activation. Chem. Rev. 2019, 119, 2192-2452. [CrossRef] [PubMed]

75. Buchwalter, P.; Rose, J.; Braunstein, P. Multimetallic Catalysis Based on Heterometallic Complexes and Clusters. Chem. Rev. 2015, 115, 28-126. [CrossRef] 